AUTARQUIA ASSOCIADA À UNIVERSIDADE DE SÃO PAULO

\title{
CICLOBUTANONAS EM RAÇÃO CANINA APÓS O PROCESSAMENTO POR
} RADIAÇÃO IONIZANTE

\section{ALEXSANDRA MARIA DE CAMPOS}

Dissertação apresentada como parte dos requisitos para obtenção do Grau de Mestre em Ciências na Área de Tecnologia Nuclear - Aplicações

Orientadora:

Profa. Dra. Anna Lucia C. H. Villavicencio 
INSTITUTO DE PESQUISAS ENERGÉTICAS E NUCLEARES

Autarquia associada à Universidade de São Paulo

CICLOBUTANONAS EM RAÇÃO CANINA APÓS O PROCESSAMENTO POR RADIAÇÃO IONIZANTE

\section{ALEXSANDRA MARIA DE CAMPOS}

Dissertação apresentada como parte dos requisitos para obtenção do Grau de Mestre em Ciências na Área de Tecnologia Nuclear - Aplicações

Orientadora:

Profa.Dra. Anna Lucia C.H. Villavicencio

Versão Original

Versão Original disponível no IPEN

São Paulo

2017 


\section{DEDICATÓRIA}

A toda minha família e em especial aos meus pais e irmãs por todo apoio que sempre me deram. 


\section{AGRADECIMENTO}

À Dra. Anna Lucia C.H. Villavicencio pela confiança e orientação que me trouxeram até aqui.

Aos professores que ao longo de minha vida contribuíram com a minha formação, e minha mãe que me apoia em todos os momentos e sempre me incentiva a continuar.

Ao IPEN, especialmente ao Centro de Tecnologia das Radiações representado pela Dra. Margarida Hamada, Gerente do CTR, Dra. Mônica Beatriz Mathor, Gerente Adjunta de Pesquisa, Desenvolvimento e Inovação e o Dr. Samir Suiz Somessari, Gerente Adjunto de Produtos e Inovação e pelo constante apoio e pré-disposição em ajudar e buscar soluções.

Aos colegas de pesquisa e todos os funcionários, pela valiosa ajuda na realização desse trabalho.

À CNEN, pelo auxílio financeiro.

Por todos aqueles que contribuíram tanto nesse trabalho, quanto na minha formação. 
"A mente que se abre a uma nova ideia jamais voltará ao seu tamanho original." Albert Einstein

Mesmo quando tudo parece desabar, Cabe a mim decidir rir ou chorar Ir ou ficar Desistir ou lutar Por que descobri No caminho incerto da vida Que o mais importante é decidir. Cora Coralina 


\title{
CICLOBUTANONAS EM RAÇÃO CANINA APÓS O PROCESSAMENTO POR RADIAÇÃO IONIZANTE
}

\author{
Alexsandra Maria de Campos
}

\section{RESUMO}

O segmento Pet, no agronegócio, está relacionado ao desenvolvimento das atividades de criação, produção e comercialização de animais de estimação. Este mercado cresceu 7,6\% entre 2014/2015, gerou R\$ 18 milhões no Brasil e $67,3 \%$ desse valor refere-se a produtos para alimentação animal, comumente chamados de Pet Food. Na alimentação animal, o alimento pode ser um único ingrediente ou uma formulação elaborada. Os ingredientes são categorizados em proteínas, carboidratos, fibras, gorduras, vitaminas e minerais. Eles são selecionados considerando os seguintes aspectos: disponibilidade, níveis de nutrientes, funcionalidade, palatabilidade, digestibilidade, custo e segurança. As matérias-primas são escolhidas de acordo com o (s) método (s) de processamento (s) em que o produto passa, sua estabilidade no processo e sua fonte nutricional durante a validade do produto. Na preservação de alimentos, o processo de irradiação é um tratamento que busca reduzir a carga microbiana dos mesmos. No entanto, também pode alterar a composição dos ingredientes presentes e formar produtos radiolíticos na formulação que ainda estão em estudo. Nos alimentos, as gorduras atuam como aporte de ácidos graxos essenciais são palatabilizantes e uma fração energética importante das rações. Nos produtos que contêm a presença de gordura, a principal preocupação são as 2-Alcilciclobutanonas (2-ACBs), que são produtos radiolíticos formados exclusivamente pós-processamento com radiação ionizante. A formação de 2ACBs está diretamente relacionada à concentração lipídica e à dose de irradiação. O objetivo deste trabalho é descrever os possíveis subprodutos 
radiolíticos formados em rações caninas extrusadas contendo gordura após irradiação e determinar se a formação de 2-ACBs depende do aumento da dose de radiação, assim como, verificar sua citotoxicidade e genotoxicidade em cães.

Palavras chave: ração canina, radiolíticos, 2-ACB, alimento irradiado, irradiação. 


\title{
CYCLOBUTANONES IN DOG FEED AFTER IONIZING RADIATION PROCESSING
}

\begin{abstract}
In agribusiness, the Pet segment is related to the development of the activities of creation, production and commercialization of pet food. This market grew 7.6\% between 2014/2015, generated $R \$ 18$ million in Brazil and $67.3 \%$ of this amount refers to products for animal feed, commonly called pet food. In animal nutrition the food may be a single ingredient or an elaborate formulation. Ingriedients are categorized into proteins, carbohydrates, fiber, fat, vitamins and minerals. They are selected considering the following aspects: availability, nutrient levels, functionality, palatability, digestibility, cost and safety. The raw materials are chosen according to the method (s) of processing (s) in which the product is submit, its stability in the process and its nutritional source during the validity of the product. In food preservation the irradiation process is a treatment that seeks to reduce the microbial load of the food. However, it can also alter the composition of the ingredients present and form radiolytic products in the formulation that are still under study. In foods, fats act as a contribution of essential fatty acids are palatabilizing and an important energetic fraction of the rations. In products containing the presence of fat, the main concern are 2- alkylcyclobutanones (2-ACBs), which are radiolytic products formed exclusively post-processing with ionizing radiation. The formation of 2-ACBs is directly related to the lipid concentration and the dose of irradiation. The objective of this work is to describe the possible radiolytic by-products formed in extruded fat-containing canine rations after irradiation and to determine if the formation of 2-ACBs is dependent on the radiation dose, and as well as verify their cytotoxicity and genotoxicity.
\end{abstract}

Key words: pet food, radiolytic, 2-BCA, irradiated food, irradiation. 


\section{SUMÁRIO}

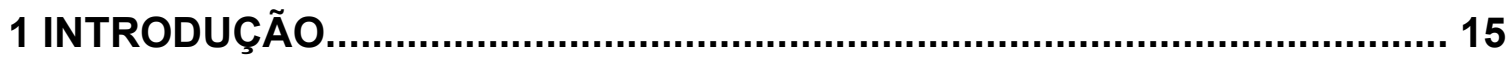

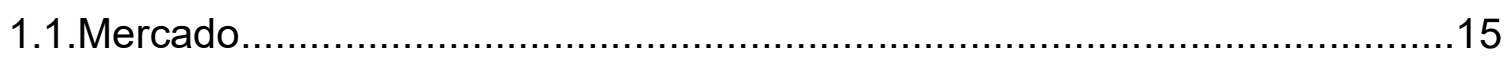

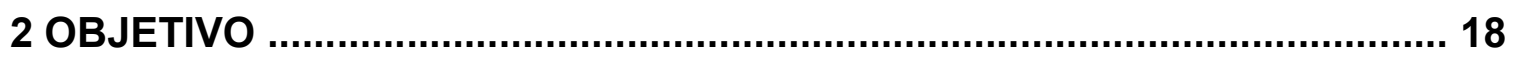

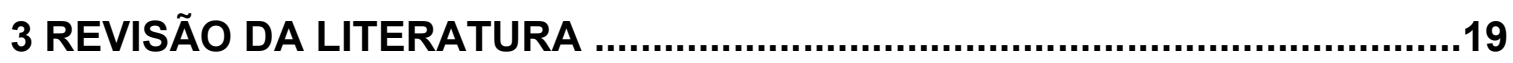

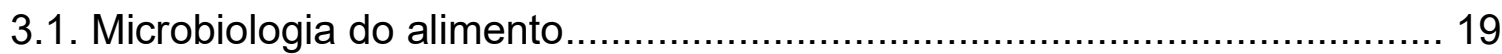

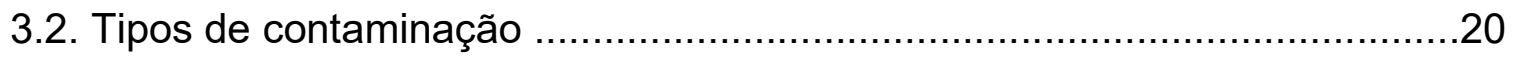

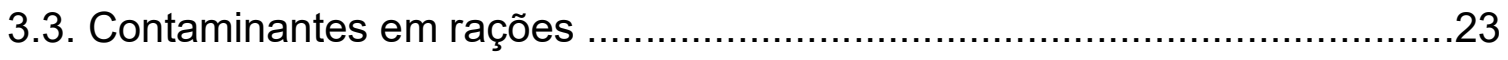

3.4. Classificação de alimentos industrializados para cães............................... 23

3.5. Exigências nutricionais para rações caninas........................................... 27

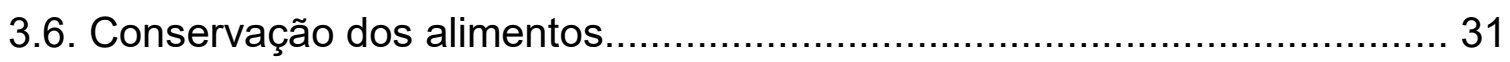

3.7. Processamento por radiação em alimentos............................................. 32

3.8. Mudanças nos lipídeos no processo de irradiação.................................... 41

3.9. Formação de 2-alcilciclobutanonas e sua relação com a dose

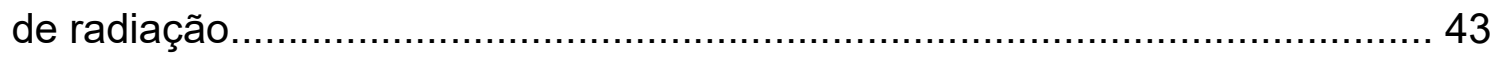

3.10. Evolução dos métodos de identificação das 2-alcilciclobutanonas............ 47

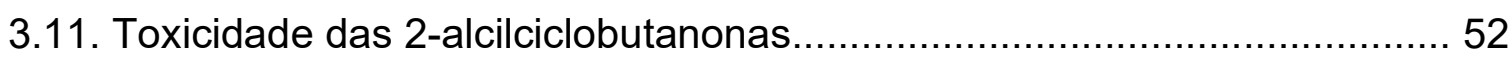

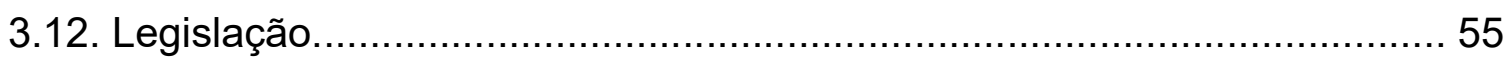

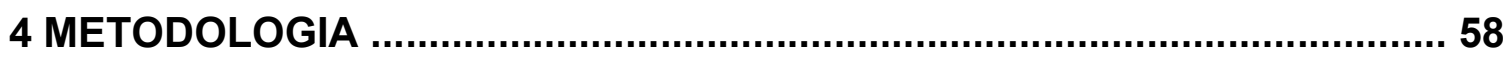

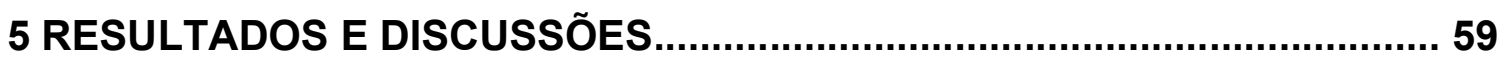

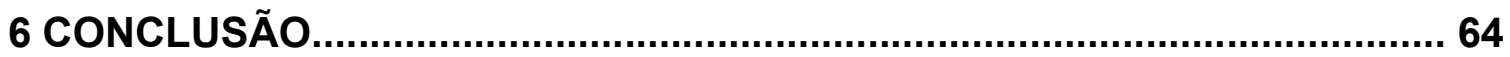

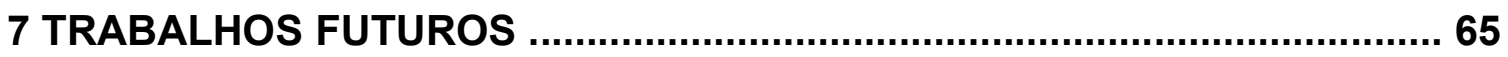

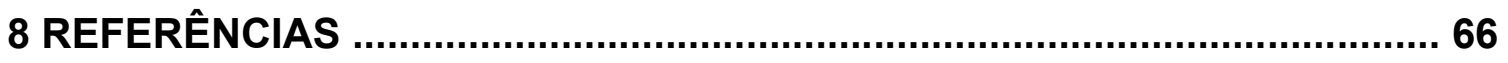




\section{LISTA DE TABELAS}

\section{PÁGINA}

TABELA 1 : Efeitos e aplicações da irradiação em alimentos............................. 37

TABELA 2: Produtos de irradiação e seus ácidos graxos precursores............... 46

TABELA 3: Normas Européia adaptada pela CEN em 1996 para Identificação

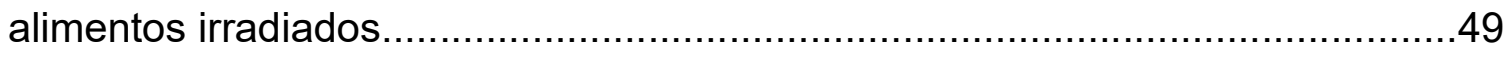

TABELA 4: Normas Européia adaptada pela CEN para identificação

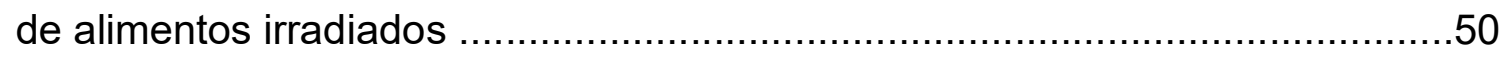

TABELA 5: Trabalhos sobre aplicação da irradiação ionizante em alimentos. 


\section{LISTA DE FIGURAS}

\section{PÁGINA}

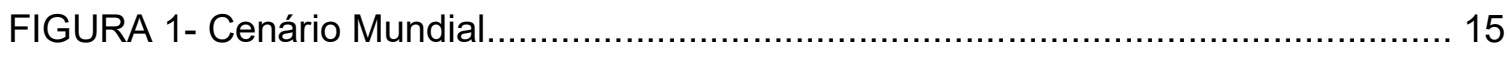

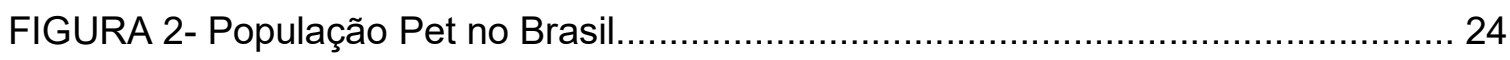

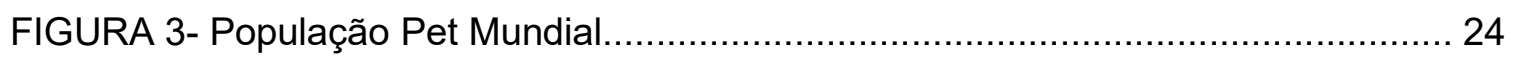

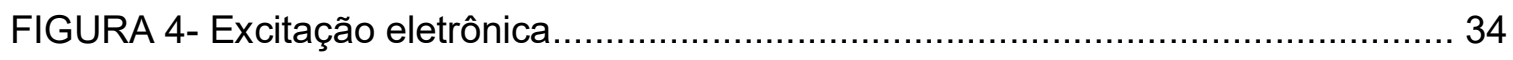

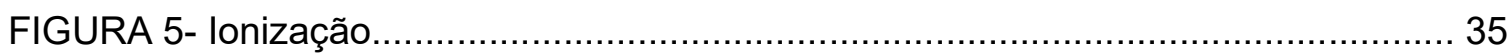

FIGURA 6- Formação de 2-ACBs a partir de triglicerídeo irradiado................................39

FIGURA 7- Exemplo de estrutura química de 2-ACBs.................................................. 40

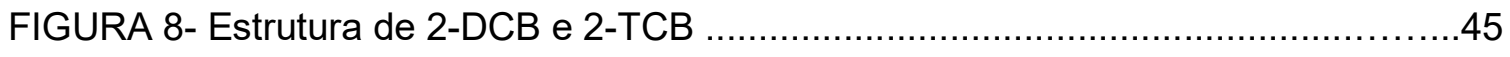

FIGURA 9 - Símbolo internacional para alimentos irradiados.................................. 56 


\section{LISTA DE ABREVIATURAS}

\begin{tabular}{|c|c|}
\hline ABINPET & $\begin{array}{l}\text { Associação Brasileira da Indústria de Produtos para } \\
\text { Animais de Estimação }\end{array}$ \\
\hline AIEA & Agência Internacional de Energia Nuclear \\
\hline ANVISA & Agência Nacional de Vigilância Sanitária \\
\hline CNE & Comitê de Normalização Europeia \\
\hline $\mathrm{FAO}$ & Organização de Agricultura e Alimentos \\
\hline FDA & Food and Drug Administration \\
\hline HACCP & Análise dos Perigos e Pontos Críticos de Controle \\
\hline $\mathrm{IA}$ & Ingestão Adequada \\
\hline IBGE & Instituto Brasileiro de Geografia e Estatística \\
\hline IIA & International Irradiation Association \\
\hline IR & Ingestão recomendada \\
\hline LSS & Limite Superior de Segurança \\
\hline MAPA & Ministério da Agricultura, Pecuária e Abastecimento. \\
\hline NR & Necessidades mínimas \\
\hline OMS & Organização Mundial de Saúde \\
\hline PET & Animais de estimação \\
\hline PET CARE & Equipamentos, acessórios, e produtos para higiene e beleza \\
\hline PET FOOD & Rações secas, úmidas e snacks \\
\hline PET VET & Medicamentos veterinários \\
\hline PNS & Pesquisa Nacional de Saúde \\
\hline WHO & World Health Organization \\
\hline
\end{tabular}




\section{INTRODUÇÃO}

\section{$1.1 \quad$ Mercado}

No agronegócio, o segmento Pet se relaciona ao desenvolvimento das atividades de criação, produção e comercialização de animais de estimação. Esse setor é dividido em Pet Food (rações secas, úmidas e snacks), Pet Care (equipamentos, acessórios, e produtos para higiene e beleza), Pet Vet (medicamentos veterinários) e Ingredientes. A população pet no Brasil é de 132,4 milhões, sendo a $4^{a}$ maior do mundo aonde há 1,56 bilhões de animais de companhia. Esse mercado cresceu 4,9\%\% entre 2015 e 2016, faturou $R \$ 18,9$ milhões e $67 \%$ desse valor refere-se a produtos para alimentação animal (pet food ) (ABINPET, 2017).

No mundo esse segmento faturou US\$ 105,3 bilhões e o Brasil representa $5,14 \%$ desse montante ocupando a $3^{\circ}$ posição no ranking mundial, atrás apenas dos Estados Unidos ( $1^{\circ}$ lugar) e do Reino Unido ( $2^{\circ}$ lugar) (ABINPET, 2017).

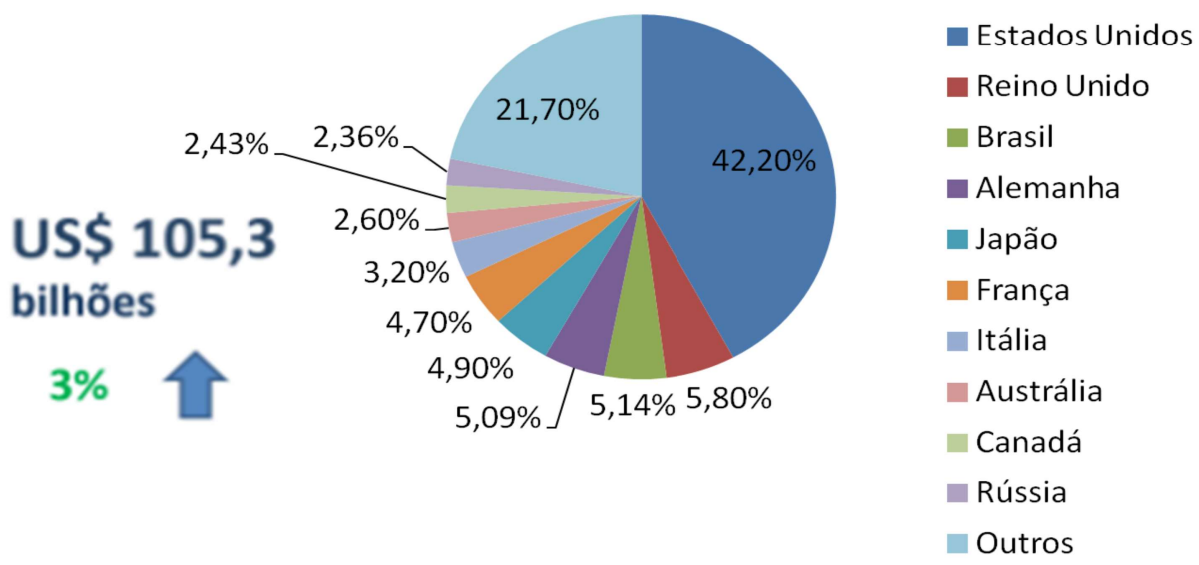

Figura 1. Cenário Mundial (Fonte: ABINPET, 2017) 
Segundo a Associação Brasileira da Indústria de Produtos para Animais de Estimação (ABINPET), um dos fatores responsáveis pelo crescimento constante do setor é o reconhecimento dos benefícios da convivência entre animais e humanos para ambos e o estilo de vida mais solitário, ou com famílias menores, das grandes cidades.

A substituição do alimento caseiro pelo produto industrializado é um sinalizador do crescimento do segmento de nutrição animal no Brasil. Os produtos para alimentação de animais de companhia, chamados comumente de "Pet food", estão em ampla expansão no mercado mundial, no qual se concentram os maiores investimentos do setor. A nutrição animal representa $67,3 \%$ do mercado total de produtos para animais de companhia no Brasil (Fortes, 2005).

No Brasil, o Ministério da Agricultura, Pecuária e Abastecimento (MAPA), tem a responsabilidade sobre a inspeção e a fiscalização dos produtos destinados à alimentação animal e é regulamentada pela Lei n 6.198 de 26 de dezembro de 1974. Essa lei é regulamentada pela Instrução Normativa $n^{\circ} 8$ que compõe o DECRETO № 6.296, de 11 de dezembro de 2007, o qual fixa e identifica as características mínimas de qualidade que estes produtos devem obedecer (BRASIL, 2007).

Segundo a Pesquisa Nacional de Saúde (PNS) realizada pelo Instituto Brasileiro de Geografia e Estatística (IBGE) em 2013, foi estimado que 44,3\% dos domicílios do País possuíam ao menos um cachorro, o que equivaleria a $28,9 \%$ dos lares brasileiros, sendo a Região Sul a de maior proporção com $58,6 \%$ e a Região Nordeste a menor com $36,4 \%$. Contudo nas áreas rurais essa proporção é de $65 \%$, superior à observada na área urbana que foi de $41,0 \%$. A população média de cachorros em domicílios brasileiros é de 1,8 cachorro/residência, o que equivale a 52,2 milhões de cachorros segundo esse estudo (IBGE, 2015).

A ABINPET registrou ao longo de 2016, uma produção de 2,58 
milhões de toneladas de pet food (ração para animais domésticos). No período de 2015 e 2016 o segmento teve um crescimento de 1,97\%. Contudo, o potencial do país é de 7,4 milhões de toneladas, o que mostra o grande potencial de crescimento do setor. O maior fator de impacto ao pleno desenvolvimento do segmento no país é a alta taxa tributária que totaliza $51,20 \%$ de tributos federais a essa categoria de produtos (ABINPET, 2016).

No Brasil todos os estados vêm crescendo nesse segmento. O Sudeste é responsável por mais de $50 \%$ do faturamento. Isso se deve, entre outras coisas, a distribuição desses produtos. Segundo a ABINPET, em 2016 o segmento faturou $\mathrm{R} \$ 18,9$ bilhões ou $5 \%$ superior a 2015 que finalizou com faturamento de $\mathrm{R} \$ 18$ bilhões. Esse montante, segundo projeção econômica pode significou $0,34 \%$ do PIB brasileiro de 2013 versus os $0,32 \%$ que este segmento representou no PIB em 2012, ou seja, uma posição superior a alguns bens duráveis como geladeira e freezer $(0,14 \%)$, eletrônicos $(0,23 \%)$ e automação industrial (0,09\%) (ABINPET, 2017).

Mundialmente, o mercado pet faturou US\$105,3 bilhões (2016), onde o Brasil participa com 5,14\%. Isso se deve ao alinhamento com as principais tendências globais, decorrentes da busca de produtos com maior valor agregado. O alimento seco, nesse mercado tem uma hegemonia e esta deve manter-se nos próximos anos. Contudo, as tendências mundiais apontam um crescimento de outras categorias como a wet (alimentos úmidos) e treat (petiscos) (ABINPET, 2017).

A relevância deste trabalho se dá pela importância econômica no Brasil e no mundo do segmento Pet Food, o crescimento vertiginoso que o segmento apresentou nos últimos anos, a afetividade que os animais de companhia representam ao homem nos dias atuais e a preocupação crescente com a saúde e bem estar animal . 


\section{OBJETIVO}

\subsection{Objetivo principal}

Compor um levantamento bibliográfico para descrever os possíveis produtos radiolíticos formados unicamente pelo processamento por radiação em rações caninas extrusadas que contenham gordura e sua possível toxicidade em cães.

\subsection{Objetivos específicos}

- Relacionar a presença de diferentes ciclobutanonas formadas unicamente pelo processo de radiação;

- Verifica se a formação de ciclobutanonas é dependente da dose de radiação;

- Descrever os grupos de ciclobutanonas formadas pelo processo de radiação em rações que contenham gordura. 


\section{REVISÃO DA LITERATURA}

\subsection{Microbiologia do alimento}

Microrganismos deteriorantes, que podem ser patogênicos ou não, são geralmente os causadores das alterações químicas nos alimentos. Essas modificações, no caso de microrganismos não patogênicos, podem ser intencionais ou não. Quando intencionais buscam trazer algum benefício ou aprimorar alguma característica do alimento, como nos processos de fabricação de queijos, pães, iogurtes, cervejas e vinhos, porém intencionalmente, estes podem também provocar alterações indesejáveis, como mau cheiro, sabor ruim e alterações da aparência dos alimentos (Bobbio e Bobbio, 2003; Franco, 2010).

A irradiação reduz a deterioração causada por microrganismos em alimentos, uma vez que, as doses utilizadas são eficientes na redução de bactérias nocivas que podem causar intoxicações alimentares. Nesse procedimento o mais importante é a dose e o tempo de exposição (Landgraf, 2002). Altas doses de irradiação, de 10 a 50 kGy são capazes de eliminar microrganismos (Crawford e Ruff, 1996).

Estando o produto com sua integridade inalterada e seguindo as boas práticas de fabricação, a irradiação se mostra eficiente no controle microbiológico. Contudo, em produtos deteriorados existe uma preocupação para que não se utilize esse processo visando mascarar essa avaria. Em um produto degradado a irradiação irá inibir o crescimento microbiológico, porém não elimina odores e degradação física que o produto já apresenta o que visualmente, já é um alerta para o consumidor (Boaratti, 2004). 


\subsection{Tipos de contaminação}

Qualquer elemento indesejável no alimento que possa comprometer sua qualidade e/ou a saúde do consumidor é considerado contaminante. O alimento está exposto a perigo quando corre risco de sofrer contaminação. Estes perigos podem ter origens variadas de acordo com o contaminante que o causa (Nerín et al, 2016, King et al, 2017).

A contaminação pode ser física, química ou biológica. A contaminação física se caracteriza pela presença de materiais estranhos ao alimento, como cabelo, pelagem de animais, vidro, plásticos, madeira, prego entre outros objetos que podem estar presentes na matéria-prima ou cair nos alimentos durante a produção (Nerín et al, 2016). A contaminação química é a presença de produtos químicos sobredosados ou tóxicos no alimento. Estes podem entrar em contato com os alimentos através das matérias-primas (agrotóxicos), serem adicionadoa a eles em quantidades perigosas, como por exemplo, no descuido da pesagem de aditivos ou na manipulação de detergentes e desinfetantes quando a limpeza é efetuada durante a produção (Nerín et al, 2016, King et al, 2017). Já a contaminação biológica é causada por seres vivos e pode ser visível ou não. Quando ela é visível normalmente é causada por insetos, como moscas e pulgões, lesmas, bem como parasitas (como lombrigas e tênias) ou serem invisíveis, como no caso dos microrganismos (BRASIL, 2001).

Em condições de conservação e armazenamento não controlado, os fungos e bactérias também são capazes de produzir toxinas patogênicas. Essa contaminação pode acontecer em qualquer parte do processo, na produção de grãos, no armazenamento da matéria-prima de origem animal, na industrialização ou na embalagem do produto final (Boermans e Leung, 2007; Souza e Scussel, 2013).

Os principais quadros de intoxicação alimentar são causados pela ingestão de toxinas produzidas por bactérias que estão presentes nos alimentos. As bactérias são responsáveis por quatro dos principais casos 
associados às intoxicações alimentares são Clostridium, Escherichia coli, Bacillus cereus e Staphylococcus. Já os problemas de intoxicação aguda, subagudas ou crônicas, são causados por micotoxinas, metabólitos secundários produzidos por fungos, e podem ser responsáveis por efeitos carcinogênicos, teratogênicos e mutagênicos em animais (Boermans e Leung, 2007). Os fungos toxigênicos podem entrar na cadeia alimentar animal pela contaminação de alimentos in natura ou processados.

Em alimentos para animais de companhia, o crescimento de microrganismos e a presença de contaminantes biológicos são determinados por vários fatores extrínsecos e intrínsecos ao próprio alimento, afetando a sua composição e qualidade. Temperatura, umidade relativa do ar, propriedades dos substratos, incluindo a umidade e a atividade de água (aw), são fatores de particular importância, além de dos fatores bióticos como presença de insetos e vertebrados (Fortes, 2005; Royal Canin, 2006).

\subsection{Contaminante em rações}

Em rações para animais de companhia a qualidade das matérias-primas é tão importante quanto a eficiência do ingrediente e/ou os nutrientes relacionados (França et al, 2011). Os principais contaminantes encontrados nos alimentos para esses animais são provenientes, principalmente, da diversidade de matérias-primas que fazem parte da composição deste alimento. Essa contaminação, muitas vezes, se dá devido à inadequada manipulação e baixa qualidade desses ingredientes. Os contaminantes biológicos comumente encontrados nesses alimentos fazem parte de diversos grupos de microrganismos (bactérias, fungos, protozoários e vírus), assim como seus metabólitos e toxinas (incluindo as toxinas bacterianas, micotoxinas e aminas biogênicas) (Landgraf, 2002, Boermans e Leung, 2007; França et al, 2011; Souza e Scussel, 2013). 
A maioria das doenças associadas aos alimentos se dá devido a contaminação por microrganismos e as bactérias, pela sua diversidade e patogenia, constituem o principal grupo microbiano. Os gêneros Salmonella, Clostridium e Escherichia coli, são os mais comumente associadas a enfermidades transmitidas por alimentos quando nos referimos a bactérias (Landgraf, 2002; Farkas, 2006; Farkas e Mohácsi-Farkas, 2011).

De importância veterinária, os fungos produzem micotoxinas em resíduos como milho, trigo, soja e arroz, ótimos substratos para seu crescimento e que são normalmente utilizados como ingredientes em rações extrusadas, causando perdas nutricionais (Boermans e Leung, 2007, 2007; França et al, 2011; Souza e Scussel, 2013). Dentre os tipos de fungo toxigênicos (produtores de micotoxina) predominam os fungos do gênero Alternaria, Cladosporium, Fusarium, Aspergillus e Penicillium (Souza e Scussel, 2013). Fígado, aparelho digestivo, rins, aparelho reprodutor e sistema nervoso central são alguns dos órgãos alvos desses fungos produtores de micotoxinas além de também exercerem efeitos no sistema imunológico e coagulação sanguínea dos animais (Boermans e Leung, 2007; França et al, 2011).

No produto final, os efeitos das micotoxinas, além da perda nutricional causam mudanças nas propriedades organolépticas e diminuição do tempo de prateleira. Em cães tem efeitos severos que podem levar a morte, pois esse tipo de animal, especificamente, quando exposto regularmente a esses contaminantes, por ter sensibilidade aos efeitos hepatotóxicos agudos, podem vir a ter danos crônicos no fígado, e consequência disso, comercialmente, a quantidade de aflatoxinas presente no produto alimentício destinado para animais é um critério de qualidade (Boermans e Leung, 2007; França et al, 2011).

A qualidade sanitária é determinada por indicadores em relação aos microrganismos dos grupo coliformes fecais e, no caso de rações, a presença de Salmonellas frequentemente encontrada em ingredientes de origem animal como farinha de carne, ossos, penas e vísceras (França et al, 2011). 
O processo de irradiação é um tratamento que busca diminuir a carga microbiana do alimento. Contudo, pode também alterar a composição dos ingredientes presentes e formar produtos radiolíticos na formulação, os quais ainda são objeto de estudo (Aquino, 2007; Caufield et al, 2008).

\subsection{Classificação de alimentos industrializados para cães}

No mundo, os cães são os principais animais escolhidos para serem animais de estimação. Isto acontece, entre outros fatores, pela transição do papel do cão na sociedade de utilitário para social. Nessa passagem, o cão se afastou de sua alimentação carnívora de seus ancestrais selvagens para adotar a alimentação fornecida pelo homem (Royal Canin, 2006). Atualmente, existem 360,8 milhões de cães no mundo sendo 52,2 milhões só no Brasil (Figura 2) (ABINPET, 2016). Em decorrência dessa população, os produtos destinados para esse mercado são variados e tem ampla expansão. Contudo, os alimentos processados correspondem a área de maior volume e investimento (Fortes, 2005). 


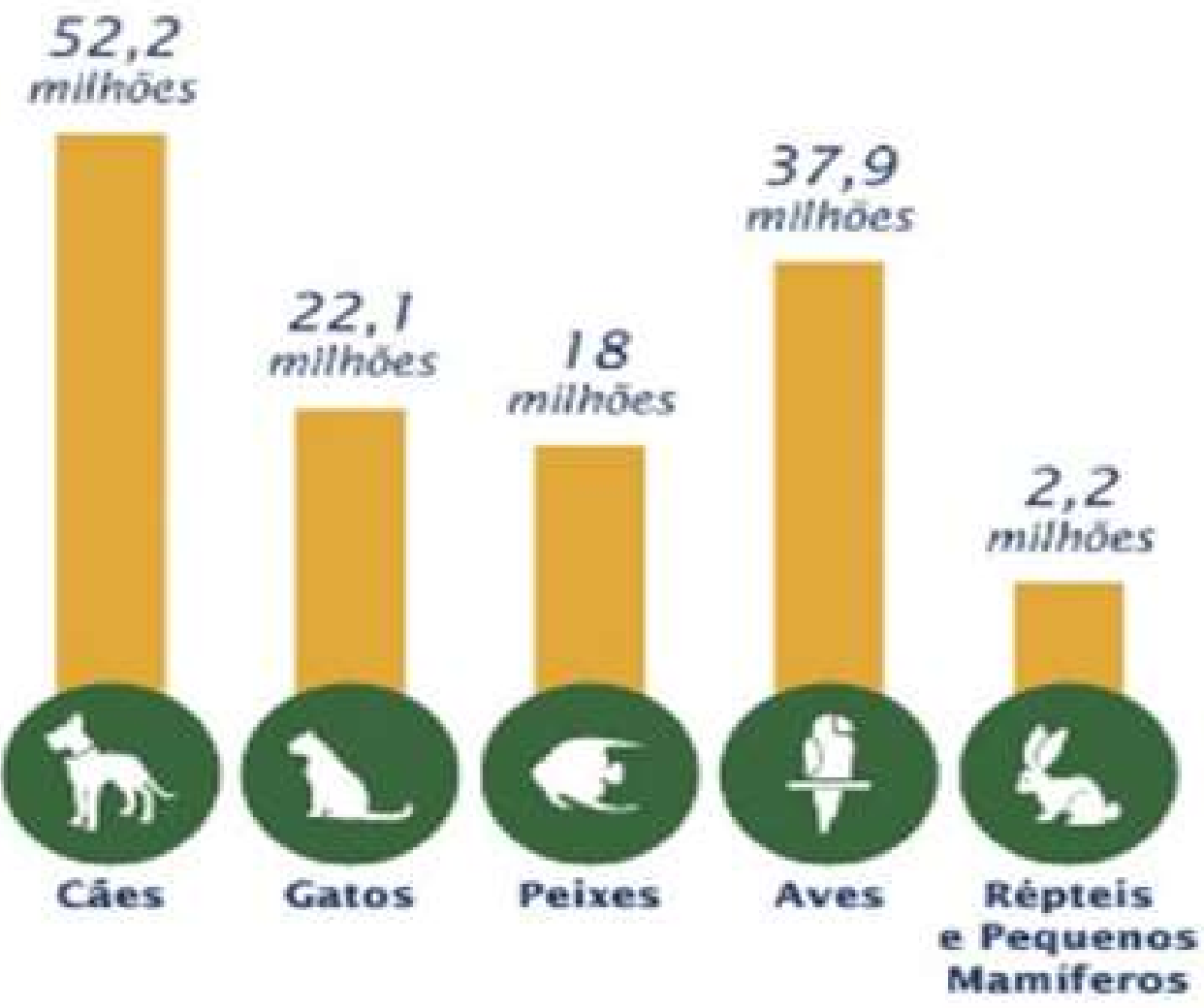

Figura 2. População Pet no Brasil. Fonte: (ABINPET, 2017)

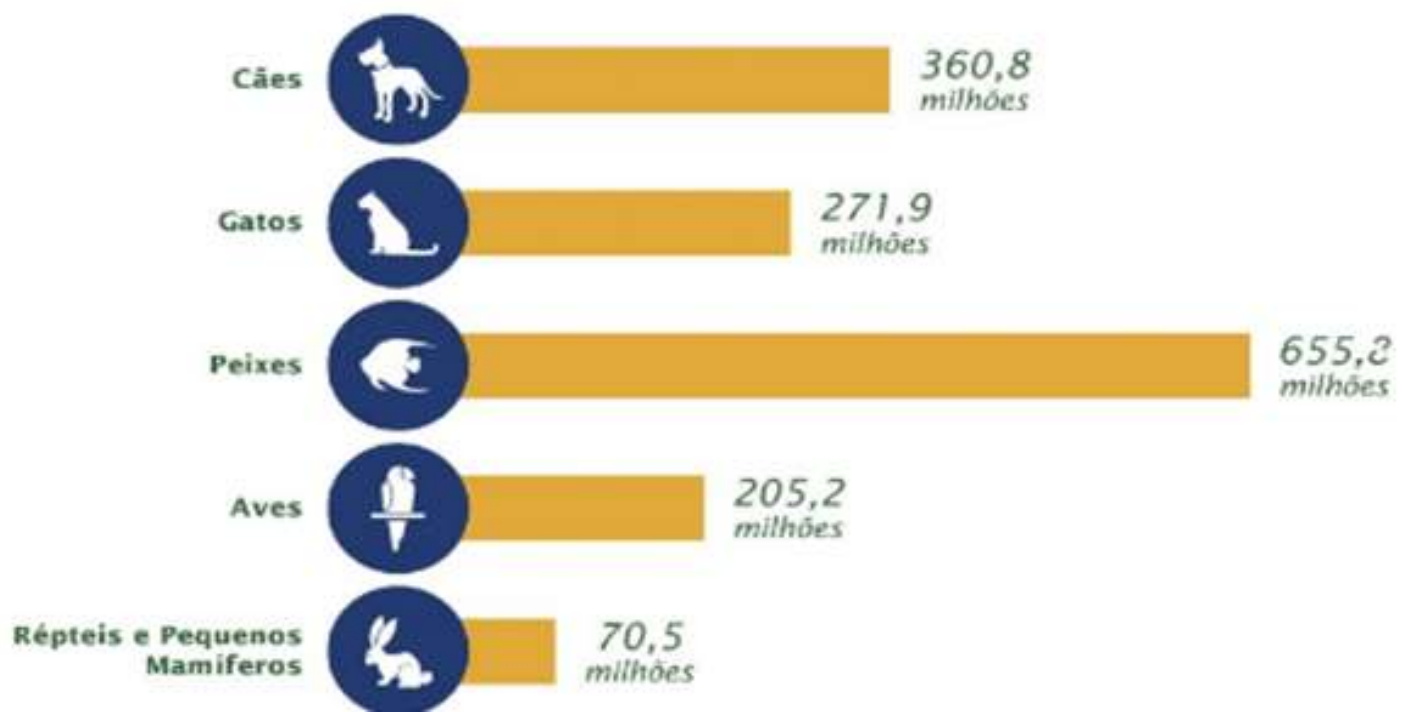

Figura 3: População Pet Mundial Fonte: (ABINPET, 2017).

No século XIX surgiu a alimentação industrial impulsionada ao reconhecimento afetivo atribuído ao cão, o que gerou um mercado especifico que expandiu e se modernizou com a evolução do estilo de vida e expectativa 
de seus proprietários que, na atualidade consideram-no como membro da família (Royal Canin, 2006). Os donos de animais gostaram da conveniência de poder comprar uma quantidade maior e dividi-la em pequenas porções, assim rapidamente esse mercado se expandiu. Durante a Segunda Guerra Mundial, contudo, com a escassez de ferro, a ração que era enlatada sofreu queda de produção, o que impulsionou no período pós-guerra o desenvolvimento e surgimento do alimento extrusado através de pesquisas da Purina (1950). Ainda se conhecia pouco sobre as necessidades nutricionais de cães e gatos e o mesmo produto era anunciado para ambos. Com aquisição de mais conhecimento sobre a fisiologia e necessidades desses animais, então, os produtos passaram a ser específicos e, nos Estados Unidos em 1990, a ração canina extrusada atingiu o topo das vendas em relação à ração enlatada. As empresas com a conquista cada vez maior de conhecimento e com a preocupação dos proprietários em nutrição e saúde passaram a desenvolver dietas elaboradas para diferentes estágios de vida, fisiologia e problemas de saúde. Um crescente número de pessoas passou a ter interesse em aprender mais sobre a legislação dos alimentos que comprava para seus animais (Case et al, 1995; Royal Canin, 2006; Carciofi e Jeremias, 2010; França et al, 2011).

$\mathrm{Na}$ atualidade, a composição das dietas comerciais caninas é normalmente composta por carboidratos, ingredientes proteicos, suplementos vitamínicos, minerais e aditivos. O excesso ou falta de algum nutriente na alimentação pode ser prejudicial a saúde do cão, pois todos os nutrientes desempenham um papel importante na dieta, assim conhecer a necessidade de cada animal é primordial para o desenvolvimento de uma formulação adequada e garantia de boa condição física e vitalidade (Royal Canin, 2006, França et al, 2011). Para se formular uma ração é necessário conhecer a legislação vigente, a classificação mercadológica do alimento, as características fisiológicas do animal, as exigências nutricionais e o processamento da ração. O Decreto 76.986 de janeiro de 1976, revogado pelo Decreto 6.296 de 11 de dezembro de 2007 contém Instruções Normativas constantemente atualizadas e é a regulamentação básica para os alimentos industrializados para cães no Brasil. Contudo, após a Instrução Normativa de $n^{\circ} 8$ de 2002, o mercado de Pet food avançou, pois neste documento estão fixados e identificados descrições das 
características mínimas de qualidade a qual os produtos industrializados devem ter (Fortes, 2005; BRASIL, 2007).

Oriundos da indústria agro-alimentícia, os alimentos industrializados destinados aos cães podem ser classificados quanto à sua função, tipo de processamento e segmentação de mercado. Quanto à função, estes alimentos podem ser completos, complementares e especiais. Os alimentos completos são aqueles que garantem na alimentação diária de cão, níveis nutricionais adequados; os complementares são os ossinhos e petiscos e os especiais são aqueles destinados a animais com distúrbios fisiológicos ou metabólicos (Case et al, 1995,Fortes, 2005, Royal Canin, 2006).

Quanto ao processamento estes alimentos podem ser úmidos (70\% a $85 \%$ de umidade) , como rações de latinhas e sachês, semiúmidos (20\% a $60 \%$ de umidade), como pellets macios e secos (menos de $12 \%$ de umidade), como rações extrusadas (Fortes, 2005; Royal Canin; 2006). Os alimentos secos, produzidos pelo processo de cozimento por extrusão, representam a maior parte do que é produzido e vendido. Nesses produtos, 30 a $60 \%$ da energia metabolizável é originada de carboidratos. Quanto à segmentação de mercado esses produtos são classificados em Econômico, Premium e Super Premium. A classificação por segmento de mercado, refere-se especificamente à flexibilidade da formulação dos produtos econômicos e Premium, que pode variar, e ao apelo de marketing (Fortes, 2005, ABINPET, 2016).

Tanto o alimento seco como o semiúmido são produzidos por extrusão e têm formulações semelhantes, compostas por carboidrato ( milho, sorgo, quirera de arroz, farelo de arroz ou trigo), proteína (farelo de soja, farinha de carne e ossos, farinha de vísceras de frango, carne fresca), gordura (gordura animal, óleos vegetais) e outros (minerais, vitaminas, corantes, palatabilizantes, antioxidantes, antifúngicos, umectantes, ácidos orgânicos).Os alimentos secos correspondem a maior parte do que é produzido e vendido no mercado, têm sua produção por processo de cozimento por extrusão, tem formulação semelhante 
ao alimento semiúmido e em média $50 \%$ de sua composição corresponde a carboidratos e apresenta umidade de 12\% (Case et al, 1995; Fortes, 2005; França et al, 2011 ).

\subsection{Exigências nutricionais em rações caninas}

Cada animal de estimação está inserido em uma estrutura familiar de pessoas com suas respectivas crenças alimentares que, recebendo também informações nutricionais da mídia, passam a se interessarem como a alimentação de seu pet pode afetar a saúde e bem-estar dele. Por isso os fabricantes devem levar em conta a necessidade nutricional dos animais, mas também as preferências de seu dono (Thompson, 2008; Carciofi e Jeremias, 2010). Ao contrário do homem, o cão aprecia os alimentos através do olfato (70 a 220 milhões de células olfativas), que é muitas vezes mais aguçado que o do homem (5 a 20 milhões de células olfativas), e tem um aparelho digestivo com 2,7 a $7 \%$ do seu peso corporal contra os $10 \%$ do aparelho digestivo do homem. Por isso tem maior dificuldade em digerir alimentos variados. O cão não mastiga seu alimento, o engole, e é no estômago que se inicia o processo de digestão, ao contrário do homem que na mastigação prepara o alimento para digestão e através dos receptores sensoriais presentes nas papilas gustativas aprecia seu sabor. A alimentação do cão é rápida, hábito ancestral que apresenta devido seu instinto de ser atacado ou ter sua alimentação roubada. O paladar canino (1.700 papilas) tem $18 \%$ menos papilas gustativas que o homem que tem cerca de 9.000 papilas e, devido a sua alimentação rápida, o alimento é deglutido e enviado para o estômago. Ou seja, o cão não aprecia os alimentos tal qual os humanos e também devido ao seu reduzido aparelho digestivo, não tem necessidade de variações de alimentos (Royal Canin, 2006). Para cães de porte médio, a ingestão diária recomendada pelos fabricantes de ração é de 200 a 350 g/dia (Caulfield et al 2008). Nos Estados Unidos (EUA) os alimentos para animais de estimação são regulamentados por órgãos federais e estaduais que monitoram a produção local e as importações (Dzanis, 2008). Na produção de 
rações são utilizados ingredientes permitidos pelas agências reguladoras de sua produção, como a ANVISA (Agência Nacional de Vigilância Sanitária) no Brasil, FDA (Food and Drug Administration) ou AAFCO (Association of American Feed Control Officials) nos Estados Unidos (EUA). As matérias-primas podem ser excluídas ou novas podem ser adicionados por estes órgãos. Em 1928 os EUA definiram os componentes que devem compor as rações e, desde então anualmente são adicionados novos elementos que surgem a partir de pesquisas, novas tecnologias de processo e também pela influência de novas culturas (Thompson, 2008).

Os alimentos para animais de estimação não podem ser adulterados. A adulteração é caracterizada quando é adicionado um produto não sancionado pelos órgãos reguladores ou encontra-se compostos químicos não permitidos, contaminação física e contaminação microbiológica (Dzanis, 2008).

No desenvolvimento do produto todo ingrediente tem uma finalidade $\mathrm{e}$ fornece algum benefício nutricional. Os ingredientes são categorizados em proteínas, carboidratos, fibras, gordura, vitaminas e minerais. Eles são selecionados considerando os seguintes aspectos: disponibilidade, níveis de nutriente, funcionalidade, palatabilidade, digestibilidade, custo e segurança. $\mathrm{Na}$ nutrição animal o alimento pode ser um único ingrediente ou uma formulação elaborada que pode ter até 60 itens em sua composição. As matérias-primas serão escolhidas de acordo com o(s) método(s) de processamento(s) do produto sua estabilidade no processo e sua fonte nutricional durante a validade do produto (Thompson, 2008).

A composição da dieta animal varia de acordo com a bioquímica nutricional da espécie a qual se destina. Segundo Caulfield et al, 2008, após o processo de irradiação há redução de vitamina $A$, além de possíveis alterações em constituintes importantes da formação em rações. Este trabalho direciona a atenção especificamente nas mudanças ocorridas com as gorduras, pois após irradiação na literatura encontramos alertas de produtos radiolíticos formados 
que podem apresentar alguma toxicidade tanto em alimentos para humanos como para animais.

A qualidade da gordura é importante para a saúde canina, pois esse nutriente auxilia no funcionamento hepático, beleza do pelo, reprodução e entre outras funções, atua como um aporte de ácidos graxos essenciais, além de ser palatabilizante e uma importante fração energética das rações. As principais fontes desse ingrediente nas rações caninas são sebo bovino, gordura de frango, óleo de milho, soja e girassol (Case et al, 1995; Fortes, 2005; Royal Canin, 2006).

Considerando como processo de produção a extrusão, que gera a ração extrusada, o alimento mais comum para a nutrição de cães, grosseiramente trata-se de um cozimento rápido na qual se usa uma combinação de calor, pressão e vapor (Case et al, 1995; Fortes, 2005; Royal Canin, 2006; Thompson, 2008). Nesse processo o nível de gordura e a fonte que entra na formulação pode afetar as características do produto final, pois influencia na taxa de expansão desse extrusado (Rokey et al, 2010).

No produto final, por lei, o rótulo deve informar uma lista contendo os ingredientes e sua proporção em ordem decrescente.Uma nutrição adequada é extremamente importante para a saúde dos animais de estimação (Case et al, 1995; Thompson, 2008).

Estudos clássicos de nutrição com as indicações dos níveis mínimos biodisponíveis, necessários para que os animais não apresentem deficiências nutricionais e tenham crescimento satisfatório, foram inicialmente reunidos e tabelados pelo "Nutrient Requirements of dog", em 1974 e posteriormente revisada em 1985 (Fortes, 2005).

Os nutricionistas questionaram essa classificação por ela apenas levar 
em consideração os nutrientes biodisponíveis, ou seja, que estivessem prontamente disponíveis para o animal, o que os obrigava a trabalhar com uma margem de segurança para poder utilizar esses parâmetros. Em 1994 a Associação Americana de Controladores de Alimentos, (AAFCO), para facilitar a formulação e controle das indústrias, passou a fornecer tabelas com as exigências nutricionais de cães e gatos já com a margem de segurança necessária, o que tornou essas tabelas mais utilizadas pela indústria Pet (Case et al 1995; Fortes, 2005). Contudo, a partir dos anos 2000 a tendência foi de buscar entendimento sobre como a nutrição poderia contribuir na promoção de saúde, bem-estar e longevidade dos cães e as necessidades mínimas deixou de ser prioridade (Carciofi e Jeremias, 2010).

As necessidades especificas de cada estágio da vida, a condição fisiológica, estilo de vida e as variadas condições fisiopatológicas dos animais tornaram-se, desde então, temas relevantes nas pesquisas para formulação de novas rações na qual a adequação da composição nutricional, a matriz dos ingredientes e seu processamento deveriam seguir parâmetros variados (Carciofi e Jeremias, 2010).

Em 2006, o Conselho Nacional de Pesquisa Norte Americano formou um comitê que reviu os 25 últimos anos de publicações sobre as necessidades nutricionais de cães e gatos e publicou a NRC 2006, que faz recomendações nutricionais com a preocupação de assegurar a qualidade de vida e longevidade, do animal. Na NRC 2006 estão reunidas todas as necessidades nutricionais para a reprodução, manutenção e os respectivos valores biodisponíveis dos nutrientes das dietas (Carciofi e Jeremias, 2010). A partir dai estabeleceram-se novas necessidades energéticas diárias que a NRC 2006 classificou em 4 categorias necessidades mínimas (NR): leva em consideração a quantidade mínima biodisponível que supre a necessidade em um respectivo estado fisiológico; ingestão adequada (IA): compreende a quantidade de nutrientes para uma determinada fase da vida; ingestão recomendada (IR): dieta para um determinado estado fisiológico; e limites superior de segurança (LSS): 
quantidade máxima que não acarreta efeitos adversos. O alimento está corelacionado com a promoção da saúde e sua ingestão ao longo de vários meses, ou anos, e relaciona a efeitos metabólicos com alterações de saúde a longo prazo (Carciofi e Jeremias, 2010).

\subsection{Conservação dos alimentos}

A conservação de alimentos é o processo de assegurar a estabilidade física, química e biológica dos alimentos, mesmo nas condições onde isso não seria viável. Esse processo não reverte nenhum quadro de deterioração já iniciado; pode sim retardá-lo, por isso o alimento a ser conservado deve chegar ao processo com boa qualidade (Farkas, 2006; Farkas e Mohácsi-Farkas, 2011). O recebimento de matéria-prima de boa qualidade é o ponto de partida para um processo de conservação ideal. Nos produtos de origem vegetal, o estágio final, colheita e transporte, são os principais responsáveis pela integridade física desse material, além, naturalmente, das condições em que estes alimentos serão armazenados antes e depois das etapas conservativas (Araújo et al, 2015; Rodrigues et al, 2012; Koike et al, 2012; Fanaro et al, 2015).

Microrganismos deteriorantes contribuem para alterações químicas geradas nos alimentos. Essas alterações químicas, nos lipídios, são causadas pelas bactérias que produzem enzimas específicas e hidrolizam sua estrutura provocando o aparecimento de ácidos graxos, compostos menores que são responsáveis, nesse caso, por odores desagradáveis aos alimentos (Brito et al, 2002). Outro responsável pelo odor pútrido (podre) são as aminas biogênicas que foram formadas pela degradação dos aminoácidos que, por sua vez, são o produto da hidrólise das proteínas. Já os carboidratos, que são fonte de energia, geram alterações sensoriais nos alimentos quando são deteriorados. A parte microbiológica dos alimentos trata das alterações que estes sofrem por microrganismos e suas toxinas, ou seja, a toxicidade alimentar e sua 
deterioração causadora das doenças alimentares nos consumidores (IAEA, 1999).

A escolha do método de conservação a ser utilizado deve levar em consideração o fator econômico, visto que é preciso produzir produtos de qualidade a preço competitivo, pois os benefícios do processo são intangíveis e não percebidos pelo consumidor que encontra, a sua disposição, uma variedade de produtos e marcas e muitas vezes faz sua escolha exclusivamente pelo preço. Dentre os vários métodos para a conservação dos alimentos a adequação do tipo de conservação ao tipo do alimento é o que difere na sua escolha (IAEA, 1999).

Para garantir a integridade física, química e nutricional dos alimentos normalmente a combinação de processos faz-se necessária. Um exemplo clássico dessa combinação de processos é o que acontece com o leite que inicialmente é tratado pelo processo de pasteurização e, posteriormente, o processo de refrigeração, combinação que lhe garante a qualidade e maior tempo para consumo (Bobbio e Bobbio, 2003; Franco, 2010).

A irradiação de alimentos é uma entre as varias tecnologias existentes que é reconhecida com um método seguro e eficaz para preservação de um amplo espectro de alimentos (Brito et al, 2002).

\subsection{Processamento por radiação em alimentos}

O termo radiação é aplicado aos processos físicos de emissão e propagação de energia. Ela pode ser classificada em ionizante (raios X, radiação emitida nas desintegrações raioativas,) e não ionizantes (calor, luz, microondas, radiação ultravioleta) (OKUNO, 1998).

A radiação que possui energia acima da energia de ligação dos elétrons do átomo no núcleo é a radiação ionizante, ela é capaz de arrancar um elétron 
de seu orbital, formando íons cátions (íon positivo). Esse elétron arrancado adquire uma energia tal que ele se desloca pelo interior da matéria, podendo interagir com outros elétrons ou núcleos, então, ele vai perdendo gradativamente sua energia e é novamente capturado por moléculas que constituem a matéria irradiada. Essa energia, propagada a um material com objetivo específico a ser atingido, é conhecida como irradiação (Araújo et al, 2015; Rodrigues et al, 2012; Koike et al, 2012; Fanaro et al, 2015).

A energia que mantém as partículas atômicas unidas é uma energia eletromagnética (Brewer, 2009). Quando a energia associada a radiação não é suficiente para arrancar elétrons e produzir íons esta é classificada como não ionizante.

Existe uma confusão entre excitação e ionização. Na excitação não ocorre a remoção de elétrons do átomo, o elétron apenas tem seu nível de energia elevado (estado excitado) e muda de orbital saindo de seu nível fundamental e ao voltar ao estado inicial, o elétron perde energia ocorrendo a emissão de luz (figura 4). A principal aplicação de alta energia é a ionização no meio absorvedor que removerá elétrons dos orbitais de seus átomos ou moléculas o que denominamos de radiação ionizante (figura 5) (Fanaro, 2013). Reações entre os componentes dos alimentos podem ser induzidas devido a irradiação que possibilita essa entrada de energia (Brewer, 2009). 

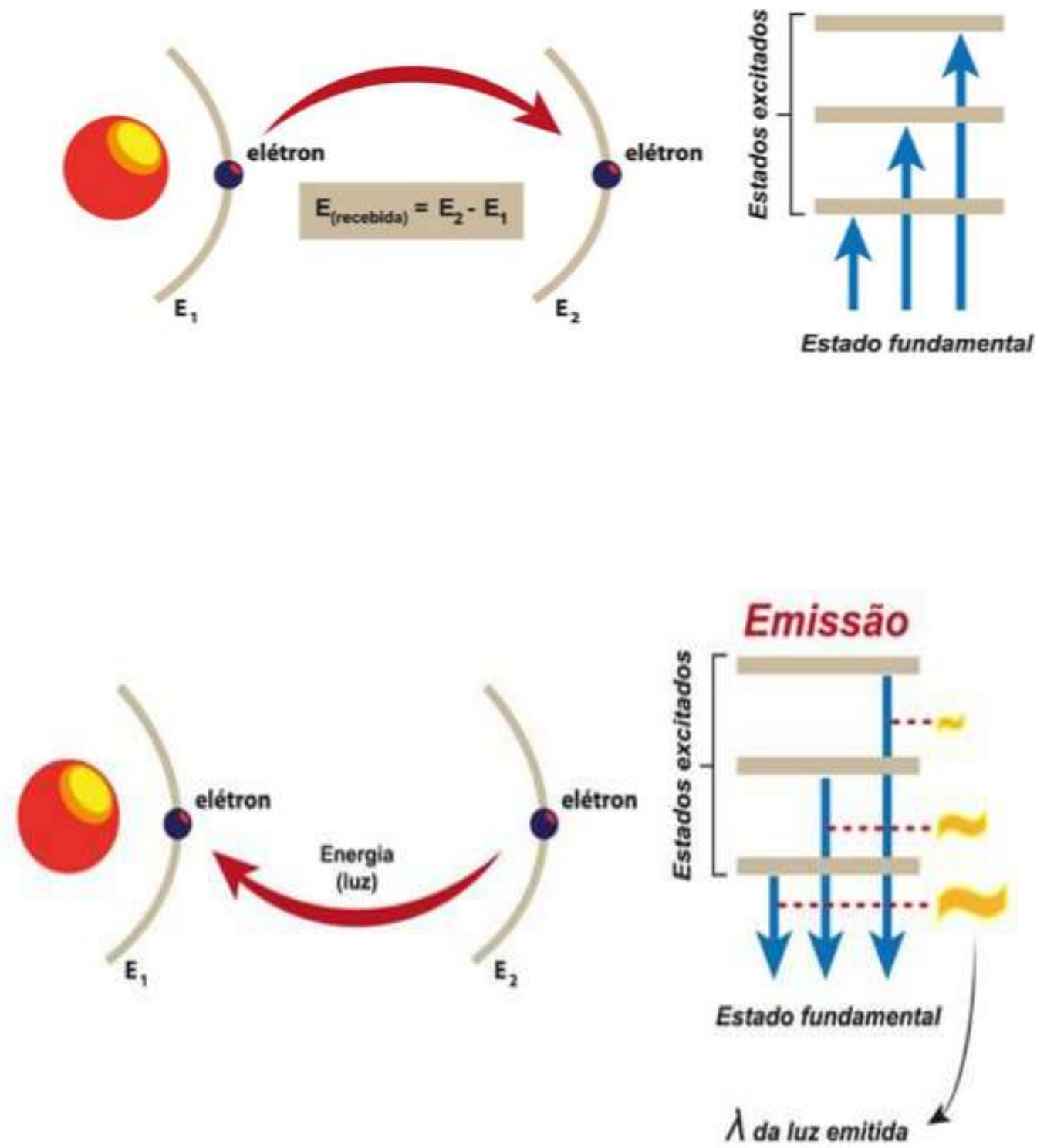

Figura 4: Excitação eletrônica. Fonte: Ciências da Natureza e suas Tecnologias Disponível em: http://slideplayer.com.br/slide/3131416/. Acesso 15 ago 2016. 


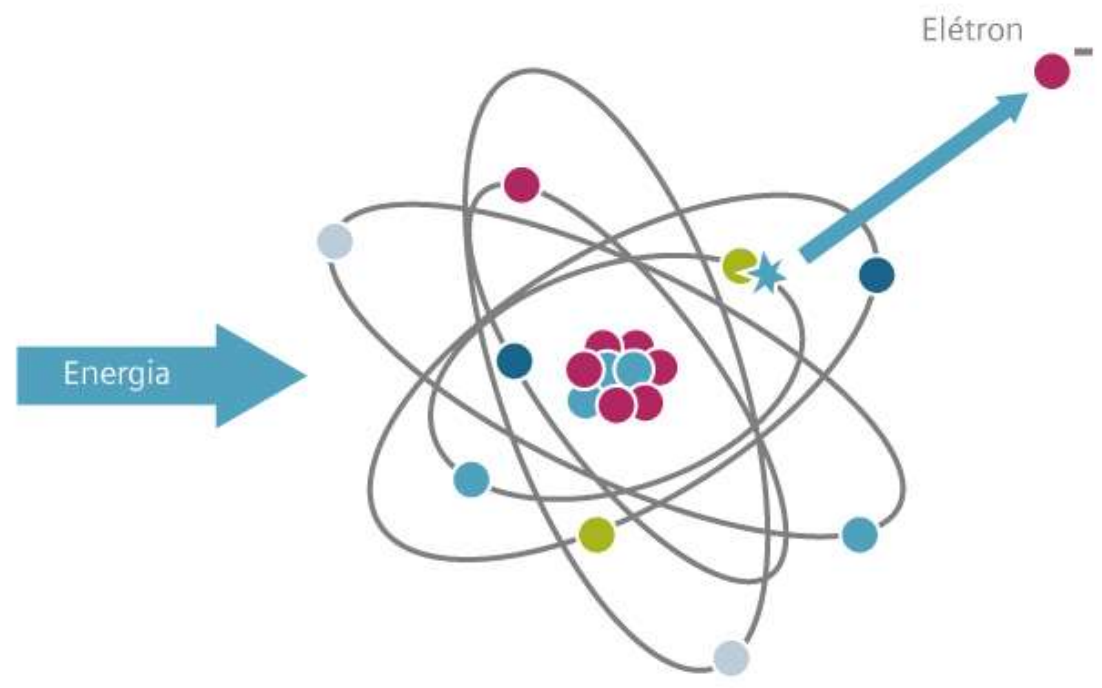

FIGURA 5: Ionização. Fonte: Site Entendendo a radicação médica. Disponível em: http://www.radiacao-medica.com.br/dados-sobre-radiacao/o-que-e-radiacao/radiacao-ionizante/ . Acesso: 30 de agosto de 2017.

A dose é a quantidade de radiação ionizante absorvida que tem como unidade o Gray (Gy) que equivale a um joule absorvido por quilo de material (Fanaro, 2013). Para aplicação em alimentos, a quantidade de radiação se faz em função da energia absorvida pelo produto irradiado e se encontra entre $0,1 \mathrm{e}$ 7,0 kGy, consiste em expor o produto, com ou sem embalagem, a uma radiação ionizante (Cardoso, 2012). Em 1981 a aplicação do tratamento de irradiação para a preservação dos alimentos foi aprovado pela FAO/ AIEA e a OMS (Giroux e Lacroix, 1998). No Brasil a Agência Nacional de Vigilância Sanitária (ANVISA) através da Resolução número 21, de 26 de janeiro de 2001, regulamentou o uso da irradiação em alimentos com objetivo de preservação desde que se utilize uma dose mínima necessária para atingir o objetivo pretendido e que esta não altere a integridade física, química e sensorial do produto (Cardoso, 2012).

Inúmeros tratamento podem ser aplicados aos alimentos para garantir sua vida de prateleira e controle microbiológico (Giroux e Lacroix, 1998). Segundo regulamenta o "Codex General Standard for irradiated Foods" (2003) em alimentos, só são permitidos os raios gama, originados de radionuclídeos de ${ }^{60} \mathrm{Co}$ que tenha energia de até $1,33 \mathrm{MeV}$ e ${ }^{137} \mathrm{Cs}$, com energia de 0,662 MeV; 
raios $\mathrm{X}$, com energia máxima de $5 \mathrm{MeV}$ e feixe de elétrons, gerados por aceleradores com capacidade de energia máxima de $10 \mathrm{MeV}$ (Farkas, 2006; Farkas e Mohácsi-Farkas, 2011).

O radionuclídeo ${ }^{60} \mathrm{Co}$ decai para níquel não radioativo por emissão de partícula alfa e raios alfa. O raio alfa é altamente penetrante, permite irradiar produtos embalados e rapidamente elimina muitos microorganismos sem tornar o produto radioativo. Em muitos minerais ocorre o ${ }^{137} \mathrm{Cs}$ não radioativo, este pode ser produzido através do processo de fissão entre o urânio e o plutônio em reator nuclear. No decaimento produzem bário não radiativo com emissão de partículas beta e gama. Partículas de alta energia podem ser produzidas através da eletricidade no acelerador de elétrons (Brewer, 2009). O processo de irradiação não torna o alimento radioativo tampouco o recupera se este estiver já deteriorado (Crawford e Ruff, 1996), sua qualidade e integridade devem estar em conformidade para que esse procedimento seja eficiente (Cardoso, 2012). É preciso analisar inicialmente qual é o objetivo que se deseja alcançar no final do processo quando tratamos um alimento por irradiação. Essa é uma opção quando se deseja um incremento no tempo de conservação, prolongamento da validade dos alimentos (shelf life) e consequentemente uma melhora no processo de distribuição e comercialização (Araújo et al, 2015; Rodrigues et al, 2012; Koike et al, 2012; Fanaro et al, 2015).

Escolhe-se a fonte para a irradiação de acordo com o material e objetivo que se deseja atingir. O processamento de alimentos por radiação, contudo, necessita um cuidado quanto ao tempo de exposição e dose. Para materiais com maior espessura normalmente se escolhe o Cobalto 60 , pois este tem grande penetrabilidade e para materiais com espessura menor ou a granel utilizam-se os aceleradores de elétrons, pois estes tem penetração em alguns milímetros de espessura (Fanaro et al,2007 a;b).

O tratamento de irradiação é largamente aplicado na indústria de alimentos na inibição de brotamento em bulbos e tubérculos, retardo de maturação e senescência em frutas e legumes, redução de carga microbiológica nas carnes, frutas e legumes, eliminação de parasitas e pragas em grãos, 
cereais, rações, frutas e especiarias e em alimentos prontos para o consumo conservados em temperatura ambiente a esterilização. Muitos alimentos são irradiados já embalados, sobretudo para que não haja recontaminação pós processamento, por isso a natureza da embalagem e sua interação com a irradiação devem ser considerados. Alguns tipos de embalagens já são rotineiramente utilizados com essa finalidade como: películas plásticas laminadas, embalagens assépticas,cortiça de garrafa etc. (Tabela 1) (IAEA, 1999).

TABELA 1: Efeitos e aplicações da irradiação em alimentos.

\begin{tabular}{|c|c|c|}
\hline Dose (kGy) & Efeitos & Exemplos de aplicação \\
\hline \multirow[t]{2}{*}{$\begin{array}{l}0,1 \text { a } 1 \\
\text { BAIXA }\end{array}$} & $\begin{array}{l}\text { I } \\
\text { inibição de brotamento } \\
\text { retardo de maturação }\end{array}$ & $\begin{array}{l}\text { tomate, cebola, alho } \\
\text { banana }\end{array}$ \\
\hline & desinfestação de pragas & carne de porco \\
\hline \multirow[t]{2}{*}{$\begin{array}{l}\text { de } 1 \text { a } 10 \\
\text { MÉDIA }\end{array}$} & $\begin{array}{c}\text { Redução de organismos } \\
\text { deteriorantes (aumento de } \\
\text { vida de prateleira) }\end{array}$ & $\begin{array}{l}\text { morango, cogumelos, } \\
\text { peixe fresco }\end{array}$ \\
\hline & $\begin{array}{c}\text { redução de patogênicos não } \\
\text { esporulados }\end{array}$ & $\begin{array}{l}\text { carne, mariscos e } \\
\quad \text { especiarias }\end{array}$ \\
\hline $\begin{array}{l}\text { acima de } 10 \\
\text { ALTA }\end{array}$ & esterilização & $\begin{array}{c}\text { especiarias, dietas } \\
\text { hospitalares, rações de } \\
\text { emergências } \\
\text { (astronautas, alpinistas) }\end{array}$ \\
\hline
\end{tabular}

Fonte: Roberts, 2014.

Independente da finalidade na qual se deseja utilizar o tratamento por irradiação é necessário que a segurança de sua aplicação seja previamente analisada. O que assegura a aplicação nesse tipo de processo é a dose na qual 
este será submetido. Essas doses são minuciosamente controladas e devem ser pesquisadas de acordo com o tempo de exposição e o tipo de alimento que será submetido a fim de se obter o objetivo com o mínimo prejuízo a integridade geral do alimento (IAEA, 1999). Contudo, como qualquer processo a que o alimento é tratado sempre existe alguma perda. Estudos identificam a formação de produtos radiolíticos, sobretudo radicais livres pós irradiação em alimentos que contém gordura (Crawford e Ruff, 1996; Delincée et al., 2002a).

Contamos com algumas técnicas para controlar e garantir a orientação natural dos alimentos. A análise sensorial, por sua vez, é responsável por mensurar o grau de perda das propriedades organolépticas a fim de que não tragam prejuízo ao sabor, odor e textura dos alimentos e permaneçam imperceptíveis ao consumidor. Outros métodos de análise de alimentos são utilizados para avaliar o valor nutricional dos alimentos bem como a integridade dos compostos bioativos presentes nos alimentos em geral. Especificamente, os métodos de detecção de alimentos irradiados são utilizados para medir perdas que o alimento pode apresentar quando tratado por irradiação. Outro importante aspecto a ter atenção são os possíveis produtos que podem ser formados exclusivamente em cada processo e como estes podem danificar ou melhorar os alimentos e influenciar na qualidade do alimento que chega ao consumidor.

Em alimentos usa-se o processamento por irradiação de forma independente ou combinada a outros processos e sua utilização tem entre as principais vantagens a diminuição do uso de produtos químicos (conservantes e antibióticos) (IAEA, 2001). Dependendo do tipo do alimento e da quantidade de energia ionizante absorvida por ele podemos ter uma variedade de resultados provenientes do processo de irradiação.

A produção de radicais livres responsáveis por alterações nutricionais e sensoriais no alimento é induzida na irradiação de lipídios, que reagem com oxigênio, levando à formação de carbonilos (Brito et al, 2002). Contudo alimentos com quantidades elevadas de gordura, a maior preocupação são as 2alcilciclobutanonas, (2-ACBs) substâncias exclusivamente produzidas pela irradiação, pois estas possuem propriedades citotóxicas que podem contribuir 
com alterações celulares e genotóxicas que podem estimular alterações no material genético das células o que sugere seu prejuízo à saúde (Delincée, 1998). Essa molécula contém número igual de carbonos $(n)$ do ácido graxo que foi originada e um grupo de hidrocarbonetos com n-4 átomos de carbono localizado na posição 2 do anel (figura 6) (Delincée, 1998; Delincée, 2002; Kim et al., 2004; Marchioni et al., 2004).
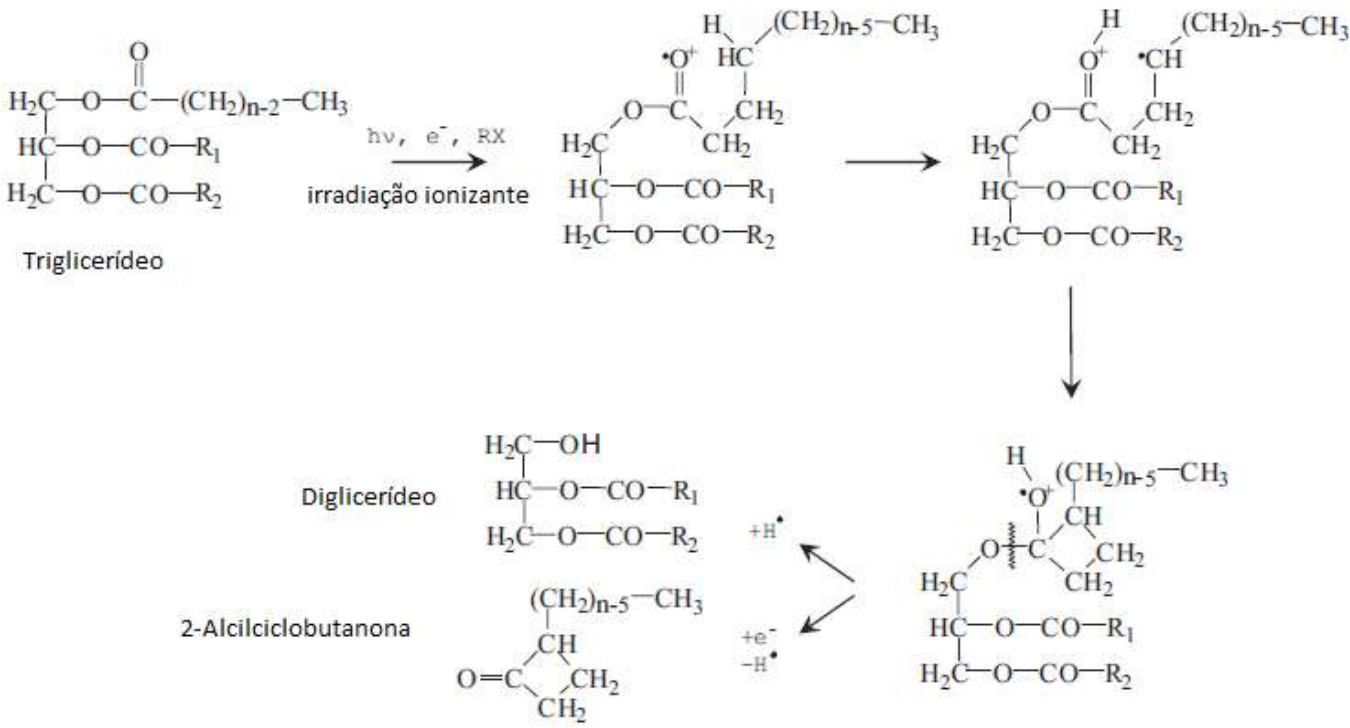

Figura 6- Formação de 2-Alcilciclobutanona a partir de triglicerídeo irradiado Fonte: Song, 2014.

As moléculas cíclicas de ACB são formadas no rearranjo quando ocorre a perda de um elétron do oxigênio da parte carbônica dos triglicerídeos ou ácidos graxos (Kim et al., 2004). Um composto diferente de ACB é formado dependendo do ácido graxo que é irradiado, conforme observado na figura 7. 


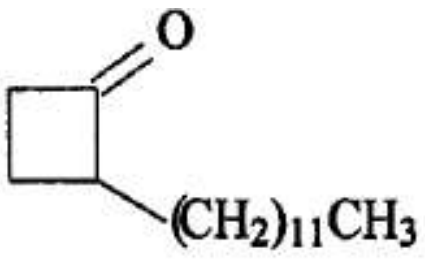

2-dodecilciclobutanona (2-dDCB)

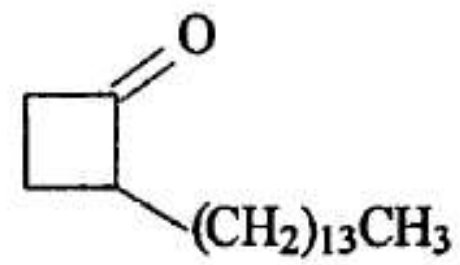

2-tetradecilciclobutanona (2-tDCB)

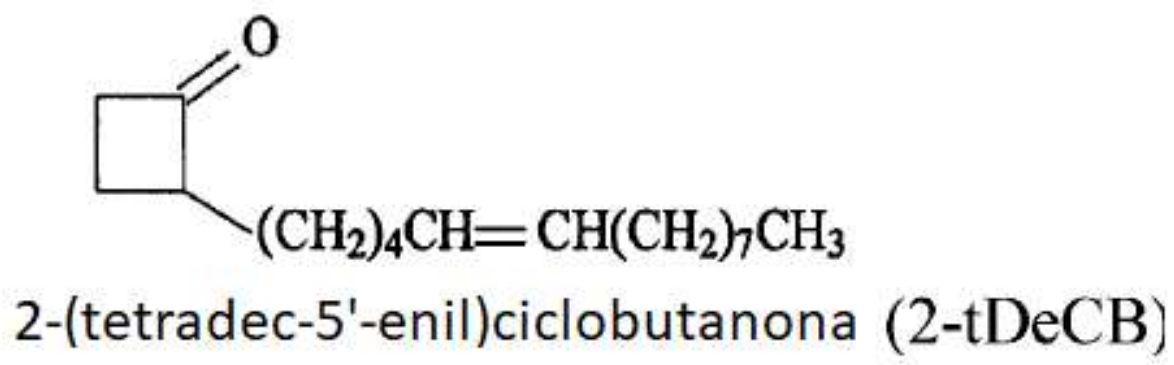

Figura 7: Exemplo de estrutura química de 2-ACBs. Fonte: Zanardi et al, 2007.

Quanto ao potencial toxicológico verificou-se através de condições experimentais in vitro risco potencial das ACB's, as quais podem promover genotoxicidade em células do cólon em ratos e humanos, contudo, observou-se uma menor formação de moléculas radiolíticas em temperaturas próximas do congelamento e na ausência de ar. Esse risco, porém, foi considerado a partir dos anos 2000 quando os estudos apresentaram risco toxicológico mesmo em concentrações muito pequenas $(0,2$ a $2 \mu \mathrm{g} / \mathrm{g}$ de gordura, dependendo da dose absorvida) pois esses alimentos podem ser consumidos no decorrer da vida (Marchioni et al.,2004; Delincée et al., 2002). 


\subsection{Mudanças nos lipídios no processo de irradiação}

Os glicídeos são a principal fonte de energia utilizada pelo metabolismo do homem. As gorduras fornecem 2,3 vezes mais calorias em peso que os carboidratos e as proteínas e algumas delas ainda têm funções biológicas no organismo (Case et al, 1995; Bobbio e Bobbio, 2003).Participam da composição de membranas, são isolantes térmicos e reserva de energia (Franco, 2010). Estão presentes em quase todas as células animais e vegetais e são facilmente extraídas com solventes orgânicos de baixa polaridade. São moléculas que tem em sua composição carbono, oxigênio e hidrogênio e algumas classes apresentam também fósforo, nitrogênio e enxofre (Case et al, 1995; Bobbio e Bobbio, 2003).

Os lipídios podem ser simples, compostos ou derivados. Os lipídios simples dão origem a somente ácidos graxos (ácidos carboxílicos com 12 ou mais átomos de carbono) e alcoóis quando submetidos à hidrólise. Os lipídios compostos contêm outros grupos na molécula, são os fosfolipídios, as ceras e os sulfolipídios e os lipídios derivados são a hidrólise dos lipídios simples e compostos na sua maioria (ácidos graxos, alcoóis, hidrocarbonetos, vitaminas lipossolúveis, pigmentos, compostos nitrogenados) (Bobbio e Bobbio, 2003). Suas propriedades físicas dependem das insaturações, ramificações e do comprimento da sua cadeia carbônica (Franco, 2010).

Em rações os lipídios fornecem energia, ácidos graxos essenciais que confere aroma e palatabilidade ao alimento. Em cães os níveis de energia da dieta é regulado pela quantidade e qualidade de sua alimentação. Pode-se selecionar um tipo que lipídio se o objetivo for obtenção de energia ou outro para se obter determinado ácido graxo, por isso geralmente utiliza-se uma mistura de duas ou mais fontes de lipídios para se ter funções distintas (França et al, 2011). 
Muitos tratamentos podem ser utilizados para auxiliar na preservação dos alimentos e garantir seu tempo de prateleira, em 1981 a irradiação foi aprovado pela FAO para essa aplicação. Os alimentos com gordura de origem animal têm predominantemente lipídios neutros (triglicerídeos), fosfolipídios, esteróis e ésteres de esteróis, sendo que os ácidos graxos saturados e monoinsaturados representam o conteúdo essencial das carnes e em carnes moídas, por exemplo, sua composição típica apresenta $18 \%$ de lipídios, sendo estes $46 \%$ composto por ácidos graxos saturados, $51 \%$ monoinsaturados e $3 \%$ poliinsaturados. Os principais ácidos graxos presente nesse tipo de alimento, que também é um ingrediente para ração canina e inúmeros pratos da dieta alimentar humana são o ácido oleico (18:1), ácido palmítico (16:0), ácido esteárico (18:0), ácido palmitoleico (16:1), ácido linoleico (18:2), ácido linolénico (18:3) e ácido araquidónico (20:4) (Giroux e Lacroix, 1998).

No metabolismo alguns ácidos graxos são de extrema importância, por exemplo, os poliinsaturados como o linoleico e o ácido araquidónico, por não serem sintetizados pelo organismo humano são essenciais na sua dieta. Fosfolipídios e colesterol, apesar de serem críticos quando encontrados nas paredes celulares apresentam importância nutricional e os ácidos graxos insaturados tem função importante no transporte das vitaminas lipossolúveis como as A, D, E e K (Giroux e Lacroix, 1998).

A auto-oxidação ocorre na presença de oxigênio nos ácidos graxos poliinsaturados, trata-se de um processo em cadeia que pode ser iniciado por variados radicais livres, inclusive os formados na irradiação. A oxidação ocorre em três etapas, sendo elas a formação dos radicais livres, a propagação e a formação de produtos não radicais, esse processo começa nos fosfolipídios e em seguida nos lipídios neutros. Os radicais livres, quando por um período prolongado estão em presença de oxigênio formam hidroperóxido que produzirão álcool, ésteres, aldeídos, ésteres de aldeídos, hidrocarbonetos, hidroxi e cetoácidos, cetonas, lactonas, oxiácidos e compostos diméricos (Giroux e Lacroix, 1998). 
Dentre os ácidos graxos, os polinsaturados são facilmente oxidados, isso ocorre porque nos lipídios suas ligações duplas são as mais facilmente atacadas, sendo que quanto maior a insaturação maior a taxa de oxidação. No processo de irradiação alterações oxidativas e não-oxidativas acontecem nos lipídios. A água, componente de muitos alimentos, sofre nesse procedimento de radiação ionizante a radiólise formando radicais livres como $\circ \mathrm{OH}^{-} \mathrm{e} \circ \mathrm{H}^{+}$que reage quimicamente com os componentes desse alimentos. Segundo, Giroux e Lacroix, 1998, o processo de radiólise é codependente do teor de gordura, sua composição, temperatura e dose de irradiação.

\subsection{Formação de 2-alcilciclobutanonas e sua relação com a dose de radiação}

A irradiação de alimentos é um procedimento utilizado em mais de 40 países e sua aplicação é adotada nos mais variados produtos, o que contribui na segurança alimentar por promover maior prazo de validade, pois inibe a maturação, permitindo a distribuição para locais mais remotos, auxilia o controle de pragas e patógenos (Lee et al, 2008), o ataque microbiano, especialmente em produtos que são comercializados sem tratamento térmico como carnes, aves e frutos do mar crus (Crews et al, 2012), além de minimizar a utilização de alguns aditivos alimentares (Lee et al, 2008).

Doses diferentes de irradiação promovem funções distintas. Para eliminar a deterioração causada por organismos patogênicos, costuma-se aplicar doses entre 1 a 7 kGy, aumentar o período de prateleira 1 a 3 kGy, para retardar o processo de amadurecimentos em frutas e vegetais frescos 0,25 a 1,0 kGy, desinfestação de insetos e parasitas 0,15 a 0,5 kGy e inibição e germinação de bulbos e tubérculos 0,05 a 0,15 kGy (Ndiaye et al, 1999; Lee et al, 2008). 
Em sistema baseados em HACCP (Análise dos Perigos e Pontos Críticos de Controle) a utilização da radiação ionizante combinada com outros procedimentos de preservação dos alimentos é vantajosa (Zanard et al, 2007). Contudo, a maior preocupação no uso desse método e a formação de compostos radiolíticos (Zanardi et al, 2007). Em 1972 por LeTellier e Nawar quando irradiavam triglicerídeos a $60 \mathrm{KGy}$ (Stevenson et al, 1993; Ndiaye et al, 1999) descobriram a formação das ACB's. Esse produto da irradiação é exclusivo desse procedimento e tornou-se identificador de alimentos irradiados (Lee et al, 2008; Delincée et al.,2002a) tendo sua detecção selecionada pelo CNE (Comitê de Normalização Europeu) como teste para identificação desse tipo de produto (Miesch et al, 1999). A aplicação desse teste conta com o elevado custo dos padrões e sua limitada variedade, pois apenas os mais usuais (2-dodecil, 2-tetradecil e 2- (tetradec-5-enil) ciclobutanonas) que tem a síntese formada pela radiólise dos ácidos graxos mais abundante nos alimentos estão disponíveis (Miesch et al, 1999). Em doses crescentes ocorre um crescimento linear de dodecilciclobutanona (Stevenson et al, 1993).

Alimentos que contenham gordura, quando tratados por feixe de elétrons acelerados, raio-x ou radiação $\gamma\left({ }^{60} \mathrm{Co}\right.$ ou $\left.{ }^{137} \mathrm{Cs}\right)$ promovem a radiólise em triglicerídeos com consequente formação de 2-alcilciclobutanonas (2-ACBs). Essas moléculas são compostos cíclicos com quatro carbonos e apresentam no total o mesmo número de carbonos do lipídio que o gerou (Lee et al, 2008), ou seja, conhecendo-se o triglicerídeo de origem é possível prever a 2-ACB que será formada (Sommers et al, 2006; Crews et al, 2012). Elas apresentam na posição 1 do anel uma cetona e na posição 2 uma ramificação Figura 8 . 0 que acontece é que na irradiação a ligação acilo-oxigênio nos acilgliceróis é clivada resultando na formação de alcanos, alcenos, lactonas, cetonas, ésteres, aldeídos e 2-ACBs (Crews et al, 2012). Até o momento, sabe-se que são formados exclusivamente, em alimentos que passaram pelo processo de irradiação. Os demais procedimentos: congelamento, pasteurização, irradiação UV, procedimentos de alta pressão entre outros não promovem tão formação 
(Sommers et al, 2006; Zanardi, 2007; Lee et al, 2008).
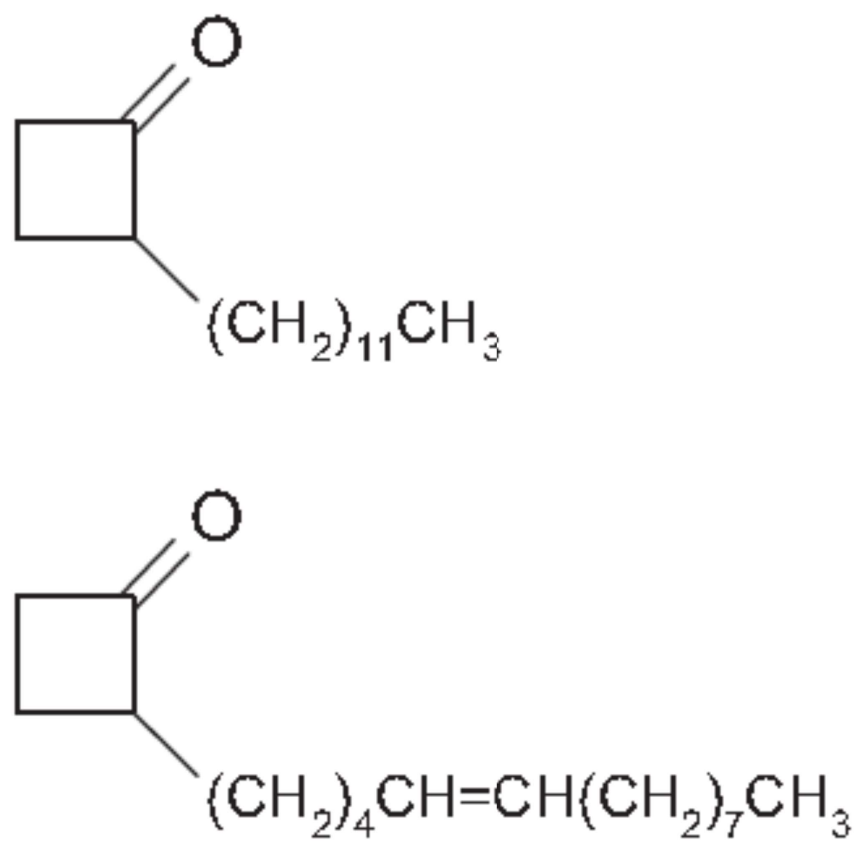

Figura 8. Estrutura de 2-DCB (acima) e 2-TCB (abaixo). Fonte: Crews et al, 2012

Na tabela 2 abaixo, são apresentados os principais ácidos graxos e os respectivos produtos de irradiação formados a partir deles. A formação de 2TCB e inferior a de 2-DCB, pois a irradiação de C18:1 monoinsaturado produz ácido 2-tetradecilciclobutanona (2-TDCB) do ácido oleico, e 2- (5 ', 8'tetradecildienil) -ciclobutanona a partir de ácido linoleico (Lee, et al, 2008). O ácido oleico é o ácido graxo mais abundante nos alimentos, ele chega a ser duas vezes mais abundante que o ácido palmítico (leite de ovelha, queijo, carne de aves) e até quatro vezes mais abundante que em ovos, abacate e mamão (Crews et al, 2012).

A formação de 2-ACBs está diretamente relacionada à concentração de lipídeo, a dose de irradiação no qual o triglicerídeo é submetido. (Sommers et al, 2006; Zanardi, 2007; Crews et al, 2012). 
TABELA 2: Produtos de irradiação e seus ácidos graxos precursores.

\begin{tabular}{lcl}
\hline \multicolumn{1}{c}{ Ácido Graxo } & $\begin{array}{c}\text { Número de } \\
\text { Carbonos }\end{array}$ & \multicolumn{1}{c}{ Produto de irradiação } \\
\hline Ácido Cáprico & C10:0 & 2-Hexilciclobutanona (2-HCB) \\
Ácido Láurico & $\mathrm{C} 12: 0$ & 2-Octilciclobutanona (2-OCB) \\
Ácido Mirístico & $\mathrm{C} 14: 0$ & 2-Decilciclobutanona (2-DCB) \\
Ácido Palmítico & $\mathrm{C} 16: 0$ & 2-Dodecilciclobutanona (2-dDCB) \\
Ácido Palmitoleico & $\mathrm{C} 16: 1$ & $\begin{array}{l}\text { Cis-2-Dodec-5-enilciclobu-tanona } \\
\text { (2-dDeCB) }\end{array}$ \\
Ácido Esteárico & $\mathrm{C} 18: 0$ & $\begin{array}{l}\text { 2-Tetradecilcilobutanona (2-tDeCB) } \\
\text { Cis-2-tetradec-5-enilciclo- } \\
\text { Autanona (2-tDeCB) }\end{array}$ \\
Monoinsaturado & $\mathrm{C} 18: 1$ & $\begin{array}{l}\text { Cis,cis-2-tetradecil-5,8-di- } \\
\text { enilciclobutanona (2-tD2eCB) }\end{array}$ \\
$\begin{array}{l}\text { Ácido Linoleico Di- } \\
\text { insaturado }\end{array}$ & $\mathrm{C} 18: 2$ & $\begin{array}{l}\text { all-cis-2-tetradecil-5,8,11- } \\
\text { trienilciclobutanona (2-tD3eCB) }\end{array}$ \\
Ácido Linolênico & $\mathrm{C} 18: 3$ \\
\hline
\end{tabular}

Fonte: Crews et al, 2012.

Os padrões sintetizados de 2-ACBs monoinsaturados são misturas $75 \%$ cis e $25 \%$ de isómeros trans, este último não presente em alimentos irradiados. $\mathrm{Na}$ espectrometria de massa o lado monoinsaturado aparece mais em fragmentos que o lado 2-ACBs saturados o que diminui a intensidade do sinal mesmo este sendo mais abundante, o que o torna menos utilizado como indicador de irradiação (Crews et al, 2012). 


\subsection{Evolução dos métodos de identificação das 2-alcilciclobutanonas}

Estima-se que milhões de casos de doenças alimentares, que levam à morte milhões de pessoas aconteçam no mundo todos os anos. Com o crescimento da população mundial e o aumento da demanda por alimentos em um maior número de regiões muitas patologias foram incluídas e a segurança alimentar tornou-se requisito para os órgãos governamentais responsáveis pela saúde pública (Hampson et al, 1996).

Para que as exigências legais sejam cumpridas e o consumidor seja devidamente informado e tenha assegurado seu direito de escolha os produtos irradiados devem ser corretamente identificados e analisados (Crews et al, 2012, Augustin et al, 2016).

Vários métodos estão disponíveis na literatura para identificação de um produto irradiado (Crews et al, 2012).Um método de detecção ideal para irradiação deve ser específico para alimentos irradiados e não para outros processos, ser reprodutível, ter baixo limite de detecção de dose mínima, ser aplicado em uma variedade de produtos, ter fácil execução, possibilitar uma estimativa de dose absorvida e ser econômico (Stevenson et al, 1995, Kitagawa, et al 2014).

É difícil um método, na prática, conseguir atender todas as determinações de um procedimento ideal e ser aplicável a todos os tipos de alimentos, com isso as alterações físicas, químicas, microbiológicas, biológicas também são investigadas a fim de se obter confiabilidade de resultado. A Comissão do Codex Alimentarius adota como métodos gerais as normas europeias. Segundo Delincée, 1998, pela dose ser auto-controlada, visto que altas doses tem uma 
restrição sensorial alta e custo elevado é mais importante os métodos de análise qualitativa, contudo, um controle efetivo das instalações de irradiação é primordial para Boas Práticas de Irradiação (GIP). (Stevenson et al, 1995, Delincée, 1998; Breidbach e Ulberth, 2016).

No final de 1996 o Comitê Europeu de Normatização (CEN), após resultados bem sucedidos em testes, padronizou cinco procedimentos à Norma Europeia na detecção de alimentos irradiados, conforme métodos químicos, físicos e biológicos. Foram eles a termoluminescência (TL) que identifica materiais irradiados que contenham sílica, dois métodos de ressonância de elétron spin (ESR), um para alimentos que tenham ossos e outro para aqueles que contenham celulose, nesse último também o método de identificação de hidrocarbonetos e para os alimentos que contém gordura as 2alcilciclobutanonas conforme apresentado na tabela 3 (Stevenson et al, 1995, Parlato et al, 2014; Breidbach e Ulberth, 2016). 
TABELA 3: Normas Européia adaptada pela CEN em 1996 para identificação de alimentos irradiados.

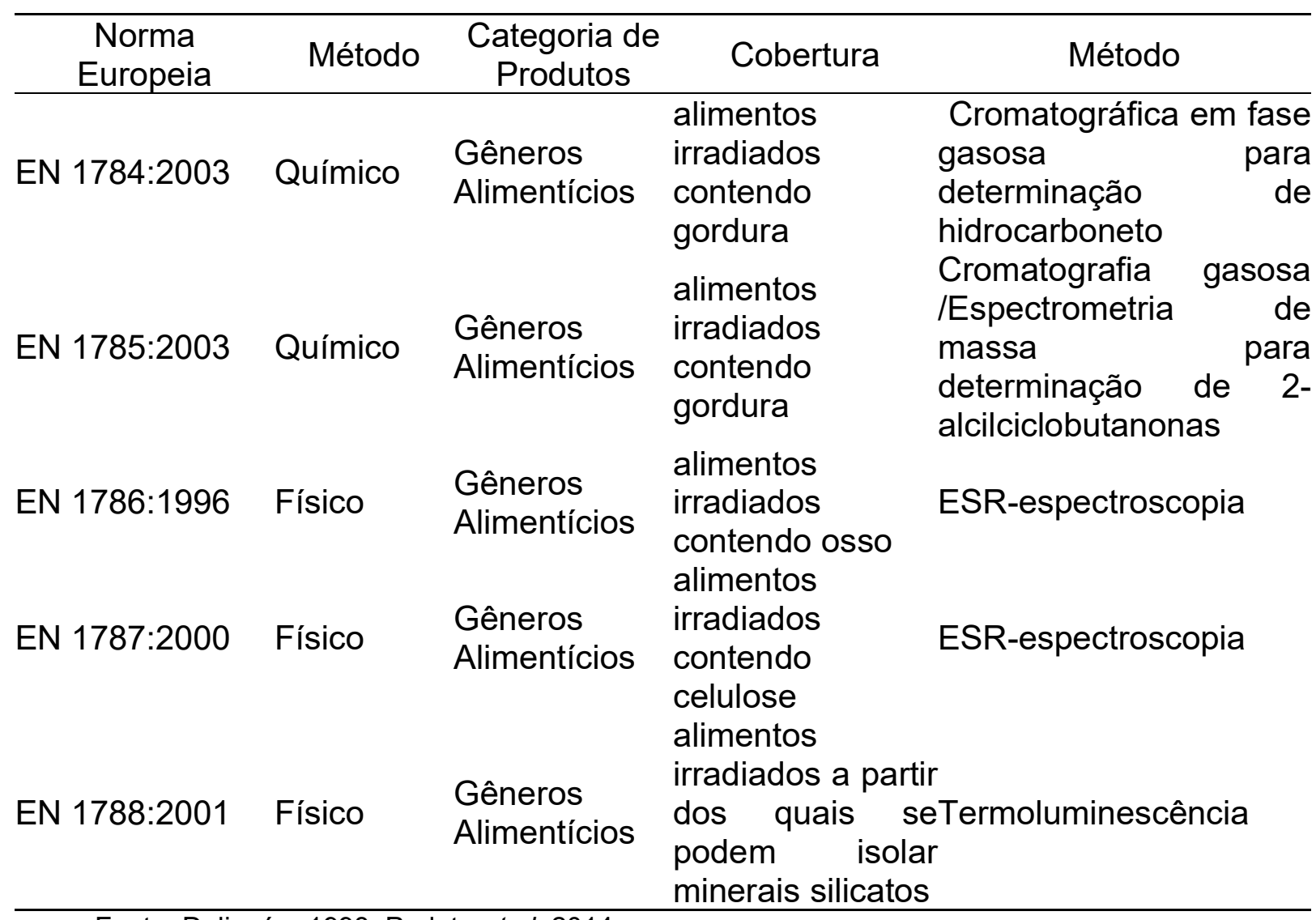

Fonte: Delincée, 1998; Parlato et al, 2014.

Posteriormente (2002 a 2004) novos métodos de triagem foram introduzidos à lista de métodos para detecção de alimentos irradiados pelo CEN, (Tabela 4) principalmente com o objetivo de confirmar resultados positivos de outros testes, visto que a composição de um alimento contém diferentes tipos de ingredientes que apresentam comportamento distinto no processo de irradiação (Parlato et al, 2014). 
Tabela 4: Normas Europeia adaptada pela CEN para identificação de alimentos irradiados

\begin{tabular}{|c|c|c|c|c|}
\hline $\begin{array}{l}\text { Norma } \\
\text { Europeia }\end{array}$ & Método & $\begin{array}{l}\text { Categoria de } \\
\text { Produtos }\end{array}$ & Cobertura & Método \\
\hline EN 13708:2001 & Físico & $\begin{array}{l}\text { Gêneros } \\
\text { Alimentícios }\end{array}$ & $\begin{array}{l}\text { alimentos irradiados } \\
\text { contendo cristais de } \\
\text { açúcar (frutas } \\
\text { cristalizadas) }\end{array}$ & $\begin{array}{l}\text { Espectroscopia de } \\
\text { ressonância de spin } \\
(E S R)\end{array}$ \\
\hline EN 13751:2002 & Físico & $\begin{array}{l}\text { Gêneros } \\
\text { Alimentícios }\end{array}$ & $\begin{array}{l}\text { alimentos irradiados } \\
\text { (mariscos, temperos e } \\
\text { ervas) }\end{array}$ & $\begin{array}{l}\text { Luminescência } \\
\text { fotoestimulada (PSL) }\end{array}$ \\
\hline & & $\begin{array}{l}\text { Gêneros } \\
\text { Alimentícios }\end{array}$ & $\begin{array}{l}\text { alimentos irradiados } \\
\text { (ervas e especiarias) }\end{array}$ & $\begin{array}{l}\text { Técnica de Filtro } \\
\text { Epifluorescente Direto }\end{array}$ \\
\hline EN 13783:2001 & Biológico & & & $\begin{array}{l}\text { / contagem de placas } \\
\text { aeróbicas (DEFT / APC) } \\
\text { - Método de seleção }\end{array}$ \\
\hline EN 13784:2001 & Biológico & $\begin{array}{l}\text { Gêneros } \\
\text { Alimentícios }\end{array}$ & $\begin{array}{l}\text { alimentos irradiados - } \\
\text { confirmar resultados } \\
\text { positivos de outras } \\
\text { normas }\end{array}$ & $\begin{array}{l}\text { DNA Comet Assay } \\
\text { Método de triagem }\end{array}$ \\
\hline EN 14569:2004 & Biológico & $\begin{array}{l}\text { Gêneros } \\
\text { Alimentícios }\end{array}$ & alimentos irradiados & $\begin{array}{l}\text { Triagem microbiológica } \\
\text { usando procedimentos } \\
\text { LAL / GNB }\end{array}$ \\
\hline
\end{tabular}

Fonte: Parlato et al, 2014.

A termoluminescência ( $T L)$ não é exclusiva para alimentos irradiados, devido os alimentos não irradiados emitirem uma baixa luminosidade faz-se uso desse procedimento para diferenciá-los. Contudo, a mostra deve estar livre de detritos minerais, pois estes componentes alteram a emissão de luz. A TL permite uma análise qualitativa e tem entre suas aplicações as especiarias irradiadas. No tratamento com radiação ionizante os alimentos formam radicais livres e quanto maior a dose maior a formação desses compostos, estes têm vida breve, porém podem ser detectados pela espectroscopia de ressonância de elétron spin (ESR) se estiverem ligados a componentes nos alimentos, e a aplicação se dá principalmente em alimentos que contém ossos, conchas, algumas frutas e especiarias, também pela ESR temos apenas a dimensão qualitativa do procedimento (Stevenson, 1992; Delincée, 1998). 
Um grande número de variações químicas são estimuladas nos ácidos graxos presentes nos alimentos pós-irradiação. Pode acontecer alterações na estrutura física e química consequentemente afetando aspectos nutricionais e sensoriais nesses alimentos. A detecção dos hidrocarbonetos formados nesses ácidos após esse procedimento foi inicialmente sugerida como método de identificação de produtos irradiados em alimentos que contenham gordura, visto que há uma relação dose-resposta o que possibilita também a análise quantitativa. A técnica original consistia em isolar os voláteis via destilação a vácuo seguida de análise cromatográfica gasosa, posteriormente técnicas alternativas de isolamento e extração dos voláteis utilizando solventes foi aplicada (Stevenson, 1992, Tewfik, 2008).

O método EN1785 é amplamente indicado para a identificação das 2ACBs e em 2007 foi introduzido como método padrão de identificação pelo governo japonês (Kitagawa et al, 2014). No alimento submetido à irradiação no qual se deseja identificar as 2-ACBs inicialmente é preciso extrair a gordura. $\mathrm{Na}$ extração de gordura muitos solventes não polares podem ser utilizados. Os comumente utilizados são hexano, éter dietílico, diclorometano, clorofórmio e acetato, contudo, os solventes clorados por apresentar risco à saúde e ao meio ambiente não são os mais indicados. Por ser extremamente volátil o éter dietílico também não é normalmente selecionado, por consequência o hexano tem maior aplicação e entra no processo Soxhlet do método EN 1785 (Norma Europeia 1785 ). O hexano é um solvente para a extração da maioria dos lipídios, tem custo baixo e pode ser recuperado (Crews et al, 2012). Nessa extração utiliza-se grande quantidade desse solvente e por ser um processo global lento a EN 1785 não é recomendado para uma triagem rápida (Tewfik, 2008, Parlato et al, 2014).

Segundo Tewfik, 2008, às dodecilciclobutanonas são facilmente detectados em todas as doses de irradiação nos alimentos com alto índice de lipídeos e sua quantidade aumenta à medida que a dose de irradiação é maior. Ainda nesse artigo conclui-se que o extração direta com solvente (DSE) pode ser utilizado em análises quantitativas e qualitativas de identificação dessa 
alcilciclobutanona e até 10 amostras podem ser extraídas num intervalo de 60 a 90 minutos o que torna esse método uma alternativa rápida de detecção de alimentos irradiados neste grupo de produtos.

A estabilidade das 2-ACBs como elemento químico isolado é pouco conhecida. Os estudos concentram-se na degradação dos alimentos irradiados. No armazenamento a oxidação surge como o vilão na perda dos compostos de 2-ACBs por lactonas e um pouco menos impactante a volatilização também contribui nessa diminuição.

\subsection{Toxicidade das 2 -alcilciclobutanonas}

Estudos sobre a segurança toxicológica de alimentos irradiados visando a sua inocuidade e nutrição data de 1950 e talvez seja uma das tecnologias de processamento mais estudadas do segmento de alimentos. Cerca de 60 países ao redor do mundo, apoiados em centenas de estudos de longa e curta duração, levaram a aprovação do processo de irradiação de alguns alimentos (Sommers et al, 2006; Song et al, 2014).

A irradiação em alimentos é um procedimento aprovado pela Organização Mundial de Saúde (OMS), pelo Food and Drug Adminstration (FDA) e também endossado por muitos países e organizações. No Codex Alimentarius 2003, a norma geral para alimentos irradiados recomenda a dose máxima absorvida até 10 kGy e acima desse valor apenas para aplicações específicas, como a esterilização de alimentos hospitalares ou em alimentos que sem refrigeração precisam ser armazenado por um período longo como a alimentação de astronautas, alpinistas e soldados (Hartiwig et al 2007). 
As 2-ACBs são formadas proporcionalmente a dose absorvida e ao teor de gordura do alimento (Hartiwig et al 2007).A baixa concentração de 2-ACBs produzidas em alimentos irradiados, 0,2 a $2 \mathrm{mg} / \mathrm{g}$ de gordura dependendo da dose absorvida, não impulsionou estudos sobre a toxicidade dessas moléculas anterior aos anos 2000, pois além de não haver normas necessárias para realizar ensaios de toxicidade se acreditava que essas pequenas quantidades não poderiam promover efeitos adversos à saúde, contudo se considerarmos os ingredientes irradiados que são adicionados aos alimentos e os próprios alimentos irradiados, isso leva a crer que o consumo de baixas concentrações de compostos radiolíticos, 2-ACBs, pode ser adquirida durante toda a vida (Manchioni et al, 2004).

A formação de 2-ACBs em função da dose de irradiação tem um padrão de crescimento linear onde a velocidade de produção é da ordem de 1,0 -1,6 $\mathrm{nmol} / \mathrm{mmol}$ do ácido graxo precursor, independente do tipo de irradiação e do precursor, o que possibilita estimar a quantidade de 2-ACBs formada por gênero alimentício. Por exemplo, a carne de frango crua submetida a $3 \mathrm{kGy}$ forma até $80 \mu \mathrm{g}$ de 2-ACBs, assim um consumo de $200 \mathrm{~g}$ da carne irradiada cozida, resulta numa ingestão de $1 \mu \mathrm{g}$ de $2-\mathrm{ACB} / \mathrm{kg}$ peso corporal. Um consumidor que tenha regularidade de consumo de produtos irradiados, pode facilmente atingir $1,5 \mu \mathrm{g} /$ dia por pessoa que até o momento é considerado um primeiro estágio da toxicidade (Hartiwig et al 2007).

Utilizando a técnica de eletroforese de microgel de célula única (Cometa Assay) para investigar o efeito de uma amostra contendo 2-dodecilciclobutanona foi observado dano no DNA celular de cólon de rato (in vitro e in vivo) e em célula de cólon de biópsia humana (Delincée, et al, 2002 a).

Ratos tratados com azoximetano, submetidos a um experimento no qual, 
por um período de 3 a 6 meses, consumiam diariamente cerca de $1 \mathrm{mg}$ de 2ACB (2-tDCB e 2-tDeCB) tiveram um efeito promotor na formação de tumores colônicos, sendo que tumores de maior tamanho foram formados nos animais que já tinham sido expostos ao carcinogêneo. A exposição de unicamente 2ACB não promoveu formação de tumores em ratos saudáveis (in vitro e in vivo), contudo, experiências com animais de laboratório comprovam a toxicidade potencial das 2-ACBs (Marchioni et al, 2004).

Segundo a biodisponibilidade de 2-ACBs, Marchioni et al, 2004, indica a presença desses radiolíticos nos tecidos adiposos e uma pequena quantidade nas fezes, o que sugere que, uma parte menor é excretada e uma outra parcela metabolizada ou armazenada nas demais partes do corpo.

As 2-ACBs apresentam efeitos citotóxicos que tem variação de acordo com a natureza dos compostos e das células, porém essas propriedades citotóxicas são evidenciadas tanto em bactérias como em células humanas, sendo mais pronunciada em bactérias. Observou-se que as 2-ACBs com menor cadeia de carbonos demonstram ter maior toxicidade (Hartwig at al, 2007).

Em estudos de citotoxicidade em bactérias, células tratadas com 2-ACBs tiveram sua capacidade de formar clones reduzida na presença de 2-DCB e 2dDCB, após uma hora de exposição. Observou-se que as bactérias tratadas com 2-DCB tiveram sobrevivência cerca de 10 vezes menos aquelas tratadas com 2-dDCB, o que comprovou a citotoxicidade crescente em bactérias (Hartiwig et al,2007).

Com as informações disponíveis até o momento é prematuro afirmar risco associado ao consumo de alimentos irradiado contendo gordura, por haver outros componentes alimentares que podem interagir com as 2-ACBs. Contudo, havendo evidências de efeitos genotóxicos e atividade promotora de tumores 
estudos mais específicos devem ser realizados (Manchioni et al, 2004).

Caulfield et al, 2008 estudou o efeito da irradiação gama na oxidação de vitaminas lipossolúveis em rações secas e relatou a drástica redução de sua porcentagem após procedimento de irradiação. Contudo, não investigou os possíveis produtos formados.

Nenhum efeito adverso associado ao consumo prolongado de alimentos irradiados, tem sido observado em animais de laboratório (Sommers et al, 2006). A alimentação com ração irradiada, de roedores de laboratório é uma prática bem consolidada, contudo, há pouca informação sobre o consumo prolongado desse tipo de alimento e sua toxicidade em cães. O FDA aceita, desde 2001, a irradiação até 50 kGy para controle microbiológico em rações. Até o presente momento tem-se apenas um estudo que relaciona o consumo prolongado de ração irradiada como possível estímulo para o surgimento de uma enfermidade em gatos, pela degradação da vitamina A (Caulfield et al, 2008). Apesar da evolução e pesquisas muitos aspectos ainda permanecem desconhecidos sobre a nutrição de cães, especificamente sobre a ingestão de alimentos irradiados ao longo de meses ou anos e os possíveis efeitos metabólicos que, associados a sua genética e estilo de vida, podem contribuir na manifestação de doenças (Carciofi e Jeremias, 2010).

\subsection{Legislação}

O tratamento de alimentos por radiação é recomendado por diversas instituições em diversos países, tais como EUR-Lex (Legislação da União Européia), "Food and Drug Administration (FDA), "Food and Agriculture Organization" (FAO), "Word Health Organization" (WHO). No Brasil, a Agência Nacional de Vigilância Sanitária (ANVISA) e o Ministério da Agricultura, Pecuária 
e Abastecimento (MAPA), sendo que cada uma delas tem distintos critérios de dose e de tipos de alimentos que podem ser tratados ( BRASIL, 2001, Dzanis, 2008).

A legislação brasileira aprova para finalidade sanitária, fitossanitária e/ou tecnológica o uso da radiação ionizante por meio da RDC n²1/2001,onde indica que a dose máxima deve ser inferior a dose que prejudique a integridade funcional e sensorial do alimento. Contudo, uma das principais observações a ser considerada ao procedimento de radiação é que este não substitui as boas práticas de fabricação e manuseio (BRASIL, 2001).

Esta resolução ainda indica que a embalagem dos alimentos deve ter condições higiênicas aceitáveis, ser adequada para o procedimento de irradiação, estar em concordância com a legislação vigente e aprovada pela autoridade sanitária competente. Sobre a informação ao consumidor na rotulagem dos alimentos, além dos dizeres exigidos para alimentos em geral e específico do alimento, deve constar com letras não inferior a um terço (1/3) da letra de maior tamanho, no painel principal os dizeres "ALIMENTO TRATADO POR PROCESSO DE IRRADIAÇÃO". Se ao invés do produto um dos seus ingredientes tenha sido irradiado, essa informação deve ser indicada entre parênteses, após o nome desse ingrediente (BRASIL, 2001) .

Internacionalmente há o símbolo da radura que identifica os alimentos que sofreram tratamento por radiação ionizante (Figura 9).( Ehlermann, 2009).

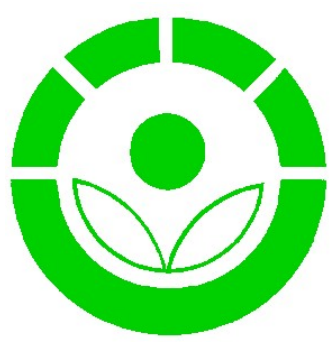

FIGURA 9 - Símbolo internacional para alimentos irradiados. Fonte: Ehlermann, 2009. 
A inspeção e fiscalização dos alimentos destinados a animais de companhia produzidos no Brasil ou importados, que são comercializados no território nacional, é de responsabilidade do MAPA que regulamenta na Lei ${ }^{\circ}$ 6.198 de 26 de dezembro de 1974 os parâmetros mínimos de qualidade que estes produtos devem apresentar (BRASIL, 2007). Contudo, essa lei e os demais decretos $\mathrm{e}$ instruções normativas brasileiras específicos para alimentação dessa categoria de animais, até a conclusão deste trabalho, não menciona nenhuma instrução sobre ingredientes irradiados adicionados a formulação ou sobre a irradiação como forma de preservação desses produtos. Encontra-se apenas na Legislação nacional parâmetros quantitativos dos nutrientes que devem compor a formulação de rações e instruções sobre as boas práticas de fabricação que garantam a integridade do produto final. 


\section{METODOLOGIA}

Para a elaboração deste trabalho foi realizado um estudo detalhado da literatura sobre os assuntos correlacionados com o tema. Através de pesquisas bibliográficas tanto em livros, periódicos, bases científicas eletrônicas, documentários e aulas expositivas no IPEN, buscou-se analisar dados comparativos dos resultados existentes tanto de revisões como de trabalhos experimentais para se verificar evidências da formação de ciclobutanonas em ração canina.

A base da consulta que resultou no presente trabalho é proveniente de bibliografias disponíveis nas bibliotecas do IPEN, Faculdade de Veterinária USP, base de dados "Science direct", "Medline", "Scielo". 


\section{RESULTADOS E DISCUSSÃO}

Após levantamento bibliográfico foi verificado que não há, até o presente momento, literatura específica sobre a aplicação da radiação ionizante em rações caninas extrusadas tanto para a aplicação do processamento por radiação quanto da identificação de ciclobutanonas.

No levantamento bibliográfico separamos alguns artigos mais relevantes ao objetivo deste trabalho no período 1992 a 2017 dos quais, confirmou-se a formação de 2-alcilciclobutanonas em alimentos que contém gordura, exclusivamente após o processamento por radiação ionizante. Na tabela 5 apresentamos os artigos utilizados no desenvolvimento deste trabalho.

TABELA 5: Trabalhos sobre aplicação da irradiação ionizante em alimentos

\begin{tabular}{|c|c|}
\hline Categoria & Autor/ Ano \\
\hline Conservação dos alimentos & Araújo et al, 2015 \\
\hline Conservação dos alimentos & Augustin et al, 2016 \\
\hline Conservação dos alimentos & Crawford et al, 1996 \\
\hline Conservação dos alimentos & Farkas, 2006 \\
\hline Conservação dos alimentos & Farkas, 2011 \\
\hline Conservação dos alimentos & Landgraf, 2002 \\
\hline Conservação dos alimentos & Koike et al, 2012 \\
\hline Conservação dos alimentos & Nerin et al, 2016 \\
\hline Detecção de alimentos irradiados & Breidabach et al, 2016 \\
\hline Detecção de alimentos irradiados & Crews et al, 2012 \\
\hline Detecção de alimentos irradiados & Delincée 2002 \\
\hline Detecção de alimentos irradiados & Delincée, 1998 \\
\hline Detecção de alimentos irradiados & Kitagawa et al, 2014 \\
\hline Detecção de alimentos irradiados & Lee et al, 2008 \\
\hline Detecção de alimentos irradiados & Miesch et al, 1999 \\
\hline Detecção de alimentos irradiados & Ndiaye, 1999 \\
\hline Detecção de alimentos irradiados & Stevenson et al, 1993 \\
\hline Detecção de alimentos irradiados & Stevenson et al, 1995 \\
\hline Detecção de alimentos irradiados & Stevenson,1992 \\
\hline Detecção de alimentos irradiados & Tewfik, 2008 \\
\hline Detecção de alimentos irradiados & Zanardi et al,2007 \\
\hline Irradiação de Alimentos & Brewer, 2009 \\
\hline
\end{tabular}


Irradiação de Alimentos Irradiação de Alimentos Irradiação de Alimentos Irradiação de Alimentos Irradiação de Alimentos Irradiação de Alimentos Irradiação de Alimentos

Irradiação de Alimentos Irradiação de Alimentos Irradiação de Alimentos Irradiação de Alimentos Irradiação de Alimentos Irradiação de Alimentos Irradiação de Alimentos

Legislação

Legislação

Legislação

Legislação

Legislação

Legislação

Legislação

Mercado

Mercado

Nutrição Animal

Nutrição Animal

Nutrição Animal

Nutrição Animal

Nutrição Animal

Nutrição Animal

Nutrição Animal

Nutrição Animal

Nutrição Animal

Química dos alimentos

Química dos alimentos

Toxicidade do alimento irradiado

Toxicidade do alimento irradiado

Toxicidade do alimento irradiado

Toxicidade do alimento irradiado

Toxicidade do alimento irradiado

Toxicidade do alimento irradiado

Toxicidade do alimento irradiado
Brito et al, 2002

Cardoso, 2012

Caulfield et al, 2008

Fanaro 2007

Fanaro et al,2007a

Fanaro et al,2007b

Fanaro, 2013

Fanaro, 2015

Girox et al, 1998

Hampson et al, 1996

Lakner et al, 2016

Okuno,1998

Roberts, 2014

Rodrigues et al, 2012

Brasil, 2001

Brasil, 2007

Dzanis, 2008

Ehlermann, 2009

IAEA, 1999

IAEA, 2001

Parlato et al, 2014

ABINPET, 2016

IBGE, 2015

Carciofi et al, 2006

Carciofi et al, 2010

Case et al, 1995

Fortes, 2005

França et al, 2011

Rokel, 2010

Royal Canin , 2006

Souza e Scussel, 2013

Thompson, 2008

Bobbio e Bobbio, 2003

Franco, 2010

Boermans et al, 2007

Delincée et al, 2002a

Hartiwing et al, 2007

King et al, 2017

Marchioni et al, 2004

Sommers et al, 2006

Song et al, 2014 
Fonte: da autora

Entre 2015 o IBGE e 2016 a ABINPET apresentaram estudos que comprovaram uma importante representação econômica do setor pet no Brasil, Este segmento de mercado teve um crescimento significativo nos últimos anos e a população de animais domésticos nos domicílios brasileiros, segundo o IBGE indica um novo estilo de vida, no qual as pessoas têm optado por ter menos filhos e informa dados que são úteis para o governo, no seu planejamento anual, por exemplo, onde precisa calcular a quantidade de vacinas que deve dispor em suas campanhas estaduais, entre outros.

Segundo a ABINPET o mercado pet faz parte de um subsegmento do agronegócio brasileiro que tem carga tributária de aproximadamente $50 \%$ e é representado por uma variedade de produtos, sendo a ração extrusada, o produto de maior volume, crescimento e renda.

Desde sua criação até os dias atuais o segmento de alimentação para animais de companhia muito se desenvolveu e conquistou a credibilidade do consumidor (proprietário), que em busca de comodidade, entende a ração como sendo alimento completo, ou seja, alimento que supre a necessidade nutricional que o cão necessita, garantido para o animal uma alimentação diária adequada para manutenção de sua saúde e bem estar (Case et al, 1995; Fortes, 2005; Carciofi et al, 2006; Royal Canin, 2006; Thompson, 2008; Carciofi et al, 2010, Rokel, 2010; França et al, 2011; Souza e Scussel, 2013).

A ração extrusada canina é um produto de fácil contaminação. Apresenta uma significativa parcela de gordura (5 até 15\%) além de uma variedade de outros ingredientes (Fortes, 2005; Carciofi et al, 2006). (Giroux et al, 1998; Okuno, 1998; Brito et al, 2002; Kim et al, 2014; Fanaro, 2007; Fanaro et al, 2007b; Caulfiel et al, 2008; Brewer, 2009; Cardoso, 2012; Rodrigues et al, 2012; Fanaro, 2013,Roberts, 2014; Fanaro, 2015; Lakner et al, 2016;).

$\mathrm{Na}$ conservação dos alimentos muitos processos podem ser utilizados. A irradiação de alimentos, na alimentação humana e animal, é uma alternativa que aliada às boas práticas de fabricação pode ser escolhida para controle 
fitossanitário, inibição de brotamento e extensão de shelf-live (Crawford et al, 1996; Farkas, 2006; Koike et al, 2012; Araújo et al, 2015; Augustin et al, 2016; Nerin et al, 2016).

No Brasil ANVISA e MAPA (Brasil, 2001; 2007) e ao redor do mundo FAO, WHO, FDA entre outros (IAEA, 1999; 2002) aprovam e indicam a irradiação no controle fitossanitário. Contudo, apesar desse procedimento também ser aplicado em rações extrusadas caninas (Caulfield et al, 2008) não há uma indicação específica para esse tipo de produto. Ainda, não há disponível,até a conclusão desse trabalho, artigo que identifique a formação de 2-alcilclobutanonas em rações, mesmo estas contendo uma porcentagem significativa de gordura em sua composição (IAEA, 1999, 2001; BRASIL, 2001, 2007 ;Dzanis, 2008 ; Erlemann, 2009; Parlato et al, 2014). Caulfield et al, 2008 identifica apenas acontecer perda das vitaminas lipossolúveis pós irradiação ionizante devido a oxidação lipídica.

No processo de irradiação de alimentos, quando este apresenta gordura na sua composição, as 2-alcilciclobutanonas (2-ACB,s) são formadas e por ser um produto exclusivo desse procedimento muitas técnicas, após a sua descoberta até os dias de hoje, tem sido desenvolvidas e aprimoradas. Segundo vários autores (Stevenson, 1992; Stevenson et al, 1993; 1995; Delincée, 1998; Miesch et al, 1999, Ndiaye, 1999; Delincée, 2002; Zanardi et al, 2007; Lee et al, 2008; Tewfik, 2008; Crews et al, 2012; Kitagawa et al, 2014; Breidabach et al, 2016) um dos desafios de aprimorar o processo de detecção é obter um procedimento eficiente, econômico e confiável em alimentos com formulações tão variadas. O teor de gordura e a dose, por exemplo, são fatores que contribuem no crescimento linear de formação das 2-ACBs (Hampson et al, 1996).

Podemos observar em nosso trabalho muitos artigos que descreveram a formação das ciclobutanonas inicialmente como um grave problema toxicológico, em particular, genotóxico. No decorrer dos últimos anos, entretanto, o tema veio se modificando e estudos mais avançados mostram que não haveria tal problema no consumo de tal espécie formada (2-ACBs), pois a quantidade 
consumida não seria tão relevante numa dieta mista na qual as gorduras estão normalmente presentes em menor proporção.

Os produtos radiolíticos formados pós-irradiação ionizante em alimentos que contém gordura, 2-ACBs, tem sua toxicidade amplamente estudada em muitos produtos do gênero alimentício. Contudo, em se tratando de nutrição animal (feed) apenas as rações destinadas a roedores utilizadas em ensaios laboratoriais receberam atenção para pesquisas com esse objetivo (Delincée et al, 2002a; Marchioni et al, 2004; Sommers et al, 2006; Boermans et al, 2007; Hartiwing et al, 2007; Song et al, 2014; King et al, 2017). É importante ressaltar, segundo indica Caulfield et al, 2008, que permitindo o FDA, desde 2001, dose de até $50 \mathrm{kGy}$ em rações para controle microbiológico é provável que muitos produtos encontrados no mercado contenham 2-ACBs e estás estejam fazendo parte da dieta de cães, sem que saibamos se de fato apresentam alguma toxicidade.

Atualmente, existe uma solicitação da International Irradiation Association (IIA) para que a Direção Geral de Saúde e Segurança Alimentar da Comissão Europeia proceda a uma avaliação das legislações relacionada à irradiação de alimentos e ingredientes alimentares, a luz das novas pesquisas e dos avanços tecnológicos conquistados, a fim de verificar se estas ainda são adequadas, para isso a IIA convocou institutos de pesquisa e toda a indústria de alimentos participante ou não da Comissão Européia, interessada em irradiação de alimentos para dar seu parecer até 03 de outubro de 2017. 


\section{CONCLUSÃO}

Conforme proposto no objetivo principal, o levantamento bibliográfico realizado nesse trabalho identificou evidências da formação de 2alcilciclobutanonas (2-ACBs) em alimentos que contem gordura e foram submetidos ao processamento por radiação ionizante.

Nos objetivos específicos pudemos concluir que:

$\checkmark$ São formadas diferentes ciclobutanonas unicamente pelo processo de radiação de alimentos que contenham gordura: 2hexilciclobutanona (2-HCB); 2-octilciclobutanona (2-OCB); 2decilciclobutanona (2-DCB); 2-dodecilciclobutanona (2-dDCB); cis2-dodec-5-enilciclobu-tanona (2-dDeCB); 2-tetradecilcilobutanona (2-tDeCB); cis-2-tetradec-5-enilciclo-butanona (2-tDeCB); cis,cis-2tetradecil-5,8-di-enilciclobutanona (2-tD2eCB); all-cis-2-tetradecil5,8,11-trienilciclobutanona (2-tD3eCB).

A formação de ciclobutanonas é dependente da dose de radiação;

$\checkmark$ Havendo a presença dos seguintes ácidos graxos precursores: ácido cáprico; ácido láurico; ácido mirístico; ácido palmítico; ácido esteárico; ácido oleico monoinsaturado; ácido linoleico diinsaturado; ácido linolênico nas rações extrusadas caninas haverá a formação das ciclobutanonas pós procedimento de irradiação ionizante. 


\section{TRABALHOS FUTUROS}

- Identificar e quantificar as 2-ACB's em ração canina;

- Estimar a quantidade ingerida de 2-ACB diária por cães;

- Verificar sua toxicidade na dieta canina;

- Alertar as autoridades havendo toxicidade comprovada. 


\section{REFERÊNCIAS}

1. ABINPET, Associação Brasileira da Indústria de Animais de Estimação, Dados de Mercado < http://abinpet.org.br/site/mercado/ > Acesso em 15 agosto 2016.

2. AUGUSTIN, M.A.; RILEY, M.; STOCKMANN, R.; BENNETT, L.; KAHL, A.; LOCKETT, T.; OSMOND, M.; SANGUANSRI, P.; STONEHOUSE, W.; ZAJAC, I.; COBIAC, L. Role of food processing in food and nutrition security, v. 56, p. 115-125, 2016.

3. ARAÚJO, M.M.; MARCHIONI, E.; VILLACICENCIO, A.L.C.H.; ZHAO, M.; PASCOLI, T.; KUNTZ, F.; BERGAENTZLE, M. Mechanism of folic acid radiolysis in aqueus solution. LWT- Food Science and Technology, v.63, p.599-603, 2015.

4. AQUINO, S. Avaliação da Microbiota fúngica e da presença de micotoxinas em amostras de plantas medicinais irradiadas adquiridas no comércio varejista e atacadista. Dissertação de Doutorado IPEN, p. 1115, 2007.

5. BOARATTI, M.F.G. Análise de perigos e pontos críticos de controle para alimentos irradiados no Brasil. Dissertação Mestrado IPEN, p. 1-112, 2004.

6. BOBBIO, F.O.; BOBBIO, P.A.; Introdução à Química de Alimentos, 3 ed. São Paulo, Livraria Varela, 2003.

7. BOERMANS, H.J.; LEUNG, M.C.K. Mycotoxins and pet food industry: Toxicological evidence and risk assessment. International Journal of Food Microbiology, v. 119, p. 95-102, 2007. 
8. BRASIL. Regulamento técnico para irradiação de alimentos. Resolução de Diretoria Colegiada - RDC n²1, Agencia Nacional de Vigilância Sanitária - ANVISA, 2001.

9. BRASIL, Inspeção e a fiscalização obrigatória dos produtos destinados à alimentação animal. DECRETO No 6.296, DE 11 DE DEZEMBRO DE 2007, Ministério da Agricultura, Pecuária e Abastecimento, MAPA, Disponível em: $<$ http://www.planalto.gov.br/ccivil 03/_Ato20072010/2007/Decreto/D6296.htm\#art4>. Acesso em: 13 mai. 2014.

10. BREIDABACH E ULBERTH, 2016, A.; ULBERTH, F.; Comparative evaluation of methods for the detection of 2-alkylcyclobutanones as indicators for irradiation treatment of cashew nuts and nutmeg. Food Chemistry, v. 201, p.52-58, 2016.

11. BREWER, M.S. Irradiation effects on meat flavor: A review, Meat Science, v. 81, p.1-14, 2009.

12.BRITO, M. S.; VILLAVICENCIO, A.L.C.H.; FILHO, J.M. Effects of irradiation on trans fatty acids formation in ground beef. Radiation Physics and Chemistry, v. 63, p..337-340, 2002.

13. CARCIOFI, A.C; VASCONCELLOS, R.S.; BORGES, N.C.; Moro, J.V.; PRADA, F.; FRAGA, V.O.; Composição nutricional e avaliação de rótulo de rações secas para cães comercializadas em Jaboticabal-SP. Arq. Bras. Med. Vet. Zootec., v.58, n.3, p.421-426, 2006.

14. CARCIOFI, A.C.; JEREMIAS, J.T. ; Progresso científico sobre nutrição de animais de companhia na primeira década do século XXI, Revista Brasileira de Zootecnia, v.39, p.35-41, 2010. 
15. CARDOSO, E. M. A Energia Nuclear (Apostila Educativa), 3 ed., p.52, Rio de Janeiro, 2012.

16. CASE,L.P.; CAREY, D.P.; HIRAKAWA, D.A. Canine and Feline Nutrition - A Resource for companion animal professionals. Mosby, 1995.

17. CAULFIELD. C. D.; CASSIDY, J.P.; KELLY, J.P Effects of Gamma Irradiation and Pasteurization on the Nutritive Composition of Commercially Available Animal Diets, Journal of the American Association for Laboratory Animal Science, v.47, n. 6, p. 61-66, 2008.

18. CRAWFORD, L, M; RUFF, E. H. A review of safety of cold pasteurization through irradiation, Food Control, v.7, n. 2, p. 87-97, 1996.

19. CREWS, C.; DRIFFIELD, M.; THOMAS, C. Analysis of 2alkylcyclobutanones for Detection of Food Irradiation: Current Status, Needs and Prospects, Journal of Food Composition and Analysis, v. 26, p.1-11, 2012.

20. DELINCÉE, $H$. Detection of food treated with ionizing radiation. Trends Food Sci. Technol., v. 9, p. 73 - 82, 1998.

21. DELINCÉE, H. Analytical methods to identify irradiated food-a review. Radiation Physics and Chemistry., v. 63, p. 455-458, 2002.

22. DELINCÉE, H.; SOIKA, C.; HORVATOVICH, P.; RECHKEMMER, G.; MARCHIONI, E. Genotoxicity of 2-alkylcyclobutanones, markers for an irradiation treatment in fat-containing food Part I: cyto- and genotoxic potential of 2-tetradecylcyclobutanone. Radiation Physics and Chemistry, v. 63, p.431-435, 2002a.

23. DZANIS, D. A. Understanding regulations affecting pet foods, Topics in Companion Animal Medicine, p.117-120, 2008. 
24. EHLERMANN, D.A.E.; The Radura-terminology and food irradiation. Food Control, v.20, p. 526-528, 2009.

25. FANARO, G.B; Efeito do processamento, por acelerador de elétrons, em grãos de soja artificialmente contaminados com Phakopsora pachyrhizi, São Paulo, 2007.

26. FANARO, G.B.; ARAÚJO, M.M.; THOMAZ, F.S.; DUARTE, R.C.; VILLAVICENCIO, A.L.C.H. Comparison of treatment in soybean grains between ${ }^{60} \mathrm{Co}$ and e-beams applications. In: International Nuclear Atlantic conference (INAC) - VIII ENAN, 2007. Proceedings. Santos, SP. Associação Brasileira de Energia Nuclear (ABEN), 2007a.

27. FANARO, G.B.; SALUM D.C.; NUNES, T.C.F; FURGERI, C.; RELA, P.; VILLAVICENCIO, A.L.C.H. Advances between e-beams and ${ }^{60} \mathrm{Co}$ applications in soybean grains. In: Eight International Topical Meeting on Nuclear Applications and Utilization of Accelerators (AccApp'07), Pocatello, Estados Unidos da América. Proceedings of International Topical Meeting on Nuclear Applications and Utilization of Accelerators, p. 1022-1025, 2007b.

28. FANARO, G.B; Efeito da radiação ionizante em chás da planta Camellia sinensis Irradiados com diferentes atividades de, 2013. Dissertação (Doutorado)- Instituto de Pesquisas Energéticas e Nucleares, São Paulo.

29. FANARO, G.B. ; Hassimotto, N.M.A. ; Bastos, D.H.M. ; Villavicencio, A.L.C.H. Effects of $\mathrm{y}$-radiation on microbial load and antioxidant proprieties in green tea irradiated with different water activities. Radiation Physics and Chemistry, February 2015, Vol.107, pp.40-46.

30. FARKAS, J.; Irradiation for better food. Trends in Food Science \& Techonology, v17, p.148-152, 2006. 
31. FARKAS,J.; MOHÁCSI-FARKAS, C. History and future of food irradiation. Tren. Food Scien. Technol., v. 22, p. 121-126, 2011.

32. FORTES, C.M.L.S; Formulação de Rações para cães. Anais do ZOOTEC'2005, maio 24-27, Campo Grande/MS, 2005, p 1-15..

33. FRANÇA, J. ;SAAD, F. M. O. B.;SAAD,C. E. P.; SILVA, R. C. ;REIS, J. S. Avaliação de ingredientes convencionais e alternativos em rações de cães e gatos, Revista Brasileira de Zootecnia, v.40, p. 222-231, 2011.

34. FRANCO, D.; Química Processos Naturais e Tecnológicos. Editora FTD, São Paulo, p. 685-690, 2010.

35. GIROUX, M; LACROIX, M. Nutritional adequacy of irradiated meat- a review, Food Research International, v. 13, n. 4, p.257-264, 1998.

36. HAMPSON, J.W. ; FOX, J.B.;LAKRITZ,L.; THAYER, D.W. Effect of Low Dose Gamma Radiation on Lipids in Five Different Meats, Meat Science, v. 42, n. 3 , p. 271-276, 1996.

37. HARTWIG, A.; PELZER, A.; BURNOUF, D.; TITÉCA, H.; DELINCÉE, H.; BRIVIBA, K.; SOIKA, C.; HODAPP, C.; RAUL, F.; MIESCH, M.; WERNER, D.; HORVATOVICH, P.; MARCHIONI, E. Toxicological potencial of 2alkylcyclobutanones- specific radiolytic products in irradiated fat-containing food- in bacteria and human cell lines. Food and Chemical Toxicology, v. 45, p. 2581-2591, 2007.

38. IAEA. International Atomic Energy Agency. Facts about food irradiation. 1999.

39. IAEA. International Atomic Energy Agency- Food irradiation with emphasis on process control and acceptance in Asia. IAEA TEC.DOC-871, 2001. 
40. IBGE. Pesquisa nacional de saúde: 2013: acesso e utilização dos serviços de saúde, acidentes e violências: Brasil, grandes regiões e unidades da federação / IBGE, Coordenação de Trabalho e Rendimento. - Rio de Janeiro: IBGE, 2015, p.100. Disponível em:< http://biblioteca.ibge.gov.br/visualizacao/livros/liv94074.pdf $>$ Acesso em 20 de agosto de 2016.

41. KIM, K.; LEE,J.; SEO, H.; KIM,J. et al. Radiolytic products of irradiated authentic fatty acids and triacylglycerides. Radiation Physics and Chemistry, v.71, p. 45-49, 2004.

42. KING, T.; COLE, M.; FARBER, J. M. ; EISENBRAND, G.; ZABARAS, D.; FOX, E.M. ; HILL, J.P. Food safety for food security: Relationship between global megatrends and developments in food safety. Trends in Food Science \& Technology, v. 68, p.160-175, 2017.

43. KITAGAWA, Y.; OKIHASHI, M.; TAKATORI, S.; KAJIMURA, K.; OBANA, H.; FURUTA, M.; NISHIYAMA, T.; A rapid and simple method for the determination of 2-alkylcyclobutanones in Irradiated meat and processed food. Food Analytic Methods, p.1066-1072, 2014.

44. KOIKE, A.C.R.; SANTILLO, A.G.; RODRIGUES, F.T.; DUARTE, R.C. VILLAVICENCIO, A.L.C.H. Evaluation of low-dose irradiation on microbiological quality of white carrots and string beans. Radiation Physics and Chemistry, v.81, p.1068-1070, 2012.

45. LAKNER,Z.; SOÓS, S.; VIDA,Z.; FARKAS,C. European research and the Hungarian school of food irradiation, Radiation Physics and Chemistry, v. 129, p. $13-23,2016$

46. LANDGRAF, M. Fundamentos e Perspectivas da Irradiação de Alimentos visando ao aumento de sua segurança e qualidade microbiológica. Tese de livre Docência Universidade de São Paulo, p. 1-87, 2002. 
47. LEE, J; KAUSAR, T; KWON, J. Characteristic Hydrocarbons and 2alkylcyclobutanones for Detecting $\mathrm{Y}$-Irradiated Sesame Seeds after Steaming, Roasting, and Oil Extraction, Journal Agriculture Food Chemistry, v. 56, p. 10391-10395, 2008.

48. MARCHIONI, E. ; RAUL, F.; BURNOUF,D.; MIESCH, M.; DELINCÉE, H.; HARTWIG, A.; WERNER, D. Toxicological study on 2-alkylcyclobutanonesresults of collaborative study, Radiation Physics and Chemistry, v. 71, p.145-148, 2004.

49. MIESCH, M.; NDIAYE, B.; HASSELMANN, C.; MARCHIONI, E. 2Alkylcyclobutanones as markers for irradiated foodstuffs -I Synthesis of saturated and unsatured standards. Radiation Physics and Chemistry, v. 55, p. 337-344, 1999.

50. NERIN,C.; AZNAR, M.; CARRIZO, D.; Food contamination during food process. Trends in Food Science \& Technology, v. 48, p.63-68, 2016.

51. NDIAYE, B; JAMET, G; MIESCH,M; HASSELMANN,C; MARCHIONI, E. 2-Alkylcyclobutanones as markers for irradiated foodstuffs. II. The CEN (European Committee for Standardization) method: field of application and limit of utilization. Radiation Physics and Chemistry, v 55, p. 437-445, 1999.

52. OKUNO, E.; Radiação: Efeitos, Riscos e Benefícios, Editora Harbra Ltda, 1988.

53. PARLATO, A.; GIACOMARRA, M.; GALATI, A.; CRESCIMANNO, M. ISO 14470: 2011 and EU legislative background on food irradiation technology: The Italian attitude. Food Science \& Technology, v. 38, p. 60-74, 2014.

54. ROBERTS, P.B. Food irradiation is safe: half a century of studies. Radiation Physics and Chemistry,v. 105, p. 78-82, 2014. 
55.RODRIGUES, Flávio T. ; Fanaro, Gustavo B. ; Duarte, Renato C. ; Koike, Amanda C. ; Villavicencio, Anna Lucia C.H. A sensory evaluation of irradiated cookies made from flaxseed meal.Radiation Physics and Chemistry, August 2012, Vol.81(8), p.1157-1159.

56. ROKEY, G.J.; PLATTNER, B.; SOUZA, E.M. Feed extrusion process description. Revista Brasileira de Zootecnica, v.39, p.510-5-18, 2010.

57. ROYAL, CANIN. Enciclopédia do Cão, Aniwa Publishing, 2006, p. 554577.

58. SOMMERS, C.H.; SMITH, J.S.; MACHIONI, E.Toxicological safety or irradiated foods. Food Irradiation Research and Technology, $1^{\mathrm{a}}$ edição, $\mathrm{p}$. 43-56, 2006.

59. SONG, B.; CHOI, S.; JIN, Y.; PARK,J.; KIM, J.; BYUN, E.; et al. A critical review on toxicological safety of 2-alkylcyclocutanones. Radiation Physics and Chemistry, v.103, p. 188-193, 2014.

60. SOUZA, K.K; SCUSSEL, V.M. Contaminantes biológicos em alimentos para animais de companhia e principais fatores de interferência. Pet Food Brasil, p.60-63, 2013. Disponível em: http://www.mflip.com.br/pub/stilo/index2/? numero=27 . Acesso em: 13 mai. 2014.

61. STEVENSON, M.H. Progress in the identification of irradiated foods. Trends in Food Science \& Technology, v.3, p.257-262, 1992.

62.STEVENSON, M.H.; CRONE, A.V.J.; HAMILTON, J.T.G.; MC MURRAY,C.H. The use of 2-docecylcyclobutanone for the identification of irradiated chicken meat and eggs. Radiation Physics and Chemistry, v. 42 , p. 363-366, 1993. 
63. STEVENSON, M.H.; STEWART, E.M.; Identification of Irradiated Food: The Current Status, Radiation Physics and Chemistry, v.46, p. 653-658, 1995.

64. TEWFIK, I. Extraction and identification of cyclobutanones from irradiated cheese employing a rapid direct solvent extraction method. International Journal of food Sciences and Nutrition, v. 59, p. 590-598, 2008.

65. THOMPSON, A.. Ingredients: Where pet food starts, Topics in Companion Animal Medicine, p. 127-132, 2008.

66. ZANARDI, E.; BATTAGLIA, A.; GHIDINI, S.; CONTER, M.; BADIANI, A.; IANIERI, A. Evaluation of 2-alkylcyclobutanones in Irradiated Cured Pork Products during Vacuum-Packed Storage, Journal Agriculture Food Chemistry, 55, p.4264-4270, 2007. 